\title{
A Participatory Approach for "Circular" Adaptive Reuse of Cultural Heritage. Building a Heritage Community in Salerno, Italy
}

\author{
Antonia Gravagnuolo (D), Serena Micheletti *(D) and Martina Bosone (D)
}

Citation: Gravagnuolo, A.;

Micheletti, S.; Bosone, M. A

Participatory Approach for "Circular"

Adaptive Reuse of Cultural Heritage. Building a Heritage Community in Salerno, Italy. Sustainability 2021, 13, 4812. https://doi.org/10.3390/ su13094812

Academic Editor: John Carman

Received: 27 January 2021

Accepted: 13 April 2021

Published: 25 April 2021

Publisher's Note: MDPI stays neutral with regard to jurisdictional claims in published maps and institutional affiliations.

Copyright: (c) 2021 by the authors. Licensee MDPI, Basel, Switzerland. This article is an open access article distributed under the terms and conditions of the Creative Commons Attribution (CC BY) license (https:// creativecommons.org/licenses/by/ $4.0 /)$.
Institute for Research on Innovation and Services for Development, National Research Council (CNR- IRISS), 80134 Naples, Italy; a.gravagnuolo@iriss.cnr.it (A.G.); m.bosone@iriss.cnr.it (M.B.)

* Correspondence: s.micheletti@iriss.cnr.it

\begin{abstract}
Cultural heritage is recognized as a key element for local sustainable development, contributing to the identity of territories and cultural diversity of local communities. The concept of "heritage community", as expressed by the Faro Convention, can be enhanced in decision-making processes for the adaptive reuse and valorization of cultural heritage to build shared and sustainable development scenarios. Communities represent fundamental actors able to drive active reflection and implement the exercise of civic responsibility and (inter)cultural policies. This paper explores how local communities can have an active and effective role in the adaptive reuse and valorization of cultural heritage, through a field experimentation conducted within the Horizon 2020 project "CLIC - Circular models Leveraging Investments in Cultural heritage adaptive reuse" in the area of Rufoli, Salerno (Italy), in the perspective of the circular economy/circular city model. Starting from heritage mapping and key stakeholder's engagement, a local working group was built, and processes of knowledge building, envisioning, and community engagement were activated. The results showed that building a heritage community can be an effective starting point for "circular" adaptive reuse of cultural heritage, stimulating not only its recovery but also community bonds, civic responsibility, and potential entrepreneurial activities for longer-term sustainable development.
\end{abstract}

Keywords: cultural heritage; heritage community; adaptive reuse; circular economy; common goods; Faro Convention

\section{Introduction}

Cultural heritage is recognized as a key element for local sustainable development, contributing to the identity of territories and cultural diversity of local communities. In this sense, the concept of "heritage community", as expressed by the 'Convention of the Value of Cultural Heritage for Society' — better known as "Faro Convention" (FC) [1,2], can be enhanced in decision-making processes for the adaptive reuse and valorization of cultural heritage to build shared and sustainable development scenarios [3]. Communities are therefore not only witnesses and vehicles of local identity values to be preserved and transmitted to future generations, but they represent fundamental actors able to drive active reflection and implement the exercise of civic responsibility and (inter)cultural policies [4].

Cultural heritage can be recognized as a driver of sustainable development in cities and regions [5-13]. The FC highlights the role that heritage communities can play to enhance cultural heritage through active conservation and valorization activities [1,2], but also the contribution of cultural heritage, tangible and intangible, for community wellbeing and economic growth. The need of conservation of cultural heritage is recognized by international charts [14-16] and national legislation. Financial resources from public bodies are allocated for the most relevant heritage buildings and sites, while "minor" and less known heritage sites receive less attention from institutions. However, minor heritage in urban peripheries and rural areas can have an important role for strengthening community 
identity, relationships, and wellbeing [17]. Small and less known heritage sites, present in almost every European city and region, have a great potential to re-activate civic attention and responsibility, while providing opportunities for sustainable growth of peripheral urban and rural areas-where the periphery should be considered as a concept, rather than as a geographic location.

Practice literature based on civic organizations reports, videos, websites, and practical experiences [18-21] reports on communities' involvement to "save" cultural heritage from abandonment through civic action. The Elinor Ostrom theory of "commons" [22] is often applied to justify the involvement of communities in heritage reuse actions through civic engagement and voluntarism [20,23]. In other cases, private organizations are able to build economic activities around heritage reuse and conservation [24], able to selfgenerate the financial resources needed for conservation and in turn to generate positive economic, social, environmental, and cultural impacts in the territory. Despite the existing practical evidence about the potential of regenerative, "circular" business models for cultural heritage adaptive reuse, few studies analyzed the potential and actual impact of minor heritage reuse through communities-based models for sustainable growth, jobs creation, and entrepreneurship $[18,20,25,26]$.

In the circular economy perspective, the abandoned and underused cultural heritage, both tangible and intangible, can turn from a "cost" to an "investment" for society, opening up new perspectives for local sustainable development, enhancing the urban landscape and communities' wellbeing, and generating new jobs. Starting from an action research approach, this paper explores how the heritage community as identified by the FC can play a significant role for the recognition, adaptive reuse, and valorization of minor cultural heritage [21], in an entrepreneurial perspective, adopting the paradigm of the circular economy/circular city $[27,28]$.

The experimentation was conducted within the Horizon 2020 project "CLIC-Circular models Leveraging Investments in Cultural heritage adaptive reuse" in the neighborhood of Rufoli, in the city of Salerno in southern Italy.

The paper is structured as follows: Section 1.1 presents the concept of cultural heritage as "common good", based on Ostrom's theory and discusses the recent implications in Italy under the experimental perspective of Regulations for the shared management of common goods; Section 2 describes the methodological approach adopted to conduct the study and the structure of the questionnaire administered in the area of Rufoli in Salerno; Section 3 analyzes the results obtained both in the knowledge phase and in the action phase with the local community; Section 4 discusses obtained results in comparison with other similar research and experimentations; finally, Section 5 discusses critical conclusions, findings, and ways forward.

\subsection{Cultural Heritage as Common Good}

The concept of "commons" (from the Latin communis) dates back to the Middle Ages [29], when it referred to an institutional agreement concerning the ownership and collective management of natural resources. In the last century, the concept of common goods has been explored to identify those goods that are not (only) public or private in terms of legal ownership, but can represent also a shared resource for communities, or even the humanity, necessary for all people and thus not subject to pure private or public management. As an example, freshwater is usually considered a "common good". The interests of communities should therefore be carefully considered in the management of common goods, often engaging them directly in their co-management [21].

Thus, the hybrid nature of "commons" poses challenges in their management, particularly regarding regulations and laws that should determine "who" has right to intervene in the management of those goods [2]. Elinor Ostrom, Nobel Prize for Economy, has tried to give an answer to this problem, highlighting how neither centralized management nor the privatization of common goods offer an ideal solution. 
However, risks have been also highlighted in the studies on common goods. One of the risks is related to the so-called "free riders", i.e., those who, by using a resource without contributing to its maintenance, threaten its survival. Social sciences have recognized a potential "Tragedy of the Commons" [30] in situations where individuals, acting independently to pursue their own personal interests, behave contrary to long-term collective interests by exploiting common goods until exhaustion. This is the case of the so-called "common-pool resources", characterized by "non-excludability" (it is not possible to exclude someone from its use) and "rivalry" (consumption by one individual precludes consumption by another individual) [31]. Based on the analysis of numerous empirical case studies, Ostrom has scientifically demonstrated that the "Tragedy of the Commons" is not inevitable: Communities can overcome the traditional dichotomy between bottom-up and top-down approach and outline a "third way" [32,33] as a prerequisite for implementing new models of cooperative management, based on the "empowerment" of the local community.

Recently the concept of "culture as a shared resource", therefore as "common good", is becoming established, as the product of a group of people or a community [32]. Unlike the common-pool resources described by Ostrom, the "cultural commons" defined by Santagata et al. [32] consist mainly of information content and therefore have the advantage of being an unlimited and non-rival resource in consumption. However, unlike common goods, they have a further disadvantage: in addition to the risk of over-exploitation by free riders, cultural good also poses the problem of transmission to future generations, requiring "management and protection in order to sustain them" [23].

The importance of Santagata's contribution to the definition of "cultural commons" is related to the identification of a close relationship among culture, space, and community interpreted as the three dimensions that, when combined together, allow to define all the possible states of cultural commons: "Culture represents the resource that is produced and managed in a commons-like framework [... T The spatial dimension reflects the environmental characteristics wherein interactions take place between community members [... ] The community, built upon an identity and symbolic dimension [34], takes into account the cohesiveness of its members and their involvement in the cultural process».

The definition of "cultural commons" therefore derives from the recognition of the interaction between the tangible and intangible components of cultural heritage and the growing role of communities in a territory or virtual space. Typical examples are the use of material heritage for cultural tourism purposes, the transmission of local traditions and know-how, the creation and management of online cultural content for virtual enjoyment.

In Italy, in 2007, the Rodotà Commission defined common goods as goods that "express a functional utility for the exercise of fundamental rights and the free development of the person" [35].

Therefore, the definition that seems to be generally shared today is that of goods that, as functional to the free development of the personality, must be accessible to all, regardless of the ability of each person to contribute to the costs incurred for their production. They can be defined as "natural but also artificial resources [...] or physical infrastructures [...], computer resources $[\ldots]$, intangible resources $[. .$.$] , provided that they are qualified by a certain$ mode of governance and management" [36].

The form of governance thus becomes an important element to determine, through a collective choice, the use of a resource as a common good. In this sense, the role of public administrations is widened, enabling and promoting initiatives and collaboration between private individuals and social operators, especially third sector actors.

Cultural heritage as "cultural common good" and its protection are at the center of the international community's interest. The Universal Convention on Human Rights [37], already in 1948, included among the rights of the individual that of "freely taking part in the cultural life of the community and enjoying the arts" (art. 27), identifying the participation of individuals as an intrinsic characteristic and a necessary part in determining the cultural identity of a community [17]. 
In recent years, the idea has emerged that each individual's right to benefit from cultural heritage is fully completed also through his or her involvement in the definition of the process, and therefore the activities, of managing and preserving cultural heritage. The Council of Europe FC [1] is part of this perspective.

Article 3 of the Convention defines "The common heritage of Europe" as "all forms of cultural heritage in Europe which together constitute a shared source of remembrance, understanding, identity, cohesion and creativity". It therefore consists of "the ideals, principles and values, derived from the experience gained through progress and past conflicts, which foster the development of a peaceful and stable society, founded on respect for human rights, democracy and the rule of law".

With respect to the right to benefit from the resource represented by cultural heritage, the Convention recognizes that "everyone, alone or collectively, has the right to benefit from the cultural heritage and to contribute towards its enrichment" having "the responsibility to respect the cultural heritage of others as much as their own heritage, and consequently the common heritage of Europe".

It is evident that also here the concept of "non-excludability" is present, while the concept of "rivalry" is interpreted as respect only for "restrictions which are necessary in a democratic society for the protection of the public interest and the rights and freedoms of others".

"The Faro Convention shifts the focus from the cultural heritage itself, to the people, their relationship with their surroundings and their active participation in the process of recognition of cultural values, placing heritage as a resource at the centre of a vision of sustainable development and promotion of cultural diversity for the construction of a peaceful and democratic society" [38]. It focuses on the identity dimension which is constituted when the community recognizes the "complex social value" of cultural heritage [39], expressing "the relational, holistic nature of being in common, which is expressed both in the landscape and in the community that is responsible and interpret of it" [40].

Knowledge and use of cultural heritage are recognized as citizens' right to participate in cultural life [37] and contribute to an identity process, which is fundamental for human development and promotion of intercultural dialogue. This process of identification between community and the place where it lives contributes to the creation of the so-called "heritage community" which "attribute values and specific aspects to cultural heritage and wish, in the framework of public action, to support them and pass them on to future generations" [1]. This highlights the social value of cultural heritage, which becomes the element that characterizes and holds a community together.

The FC underlines the importance of considering cultural heritage as an individual and collective responsibility, shared by public authorities at all levels, but also by businesses, civil society, and citizens [41]. In other words, the community itself can define and qualify cultural heritage, and organize its management as a common resource [21]. This represents a turning point in the management of cultural heritage, ratifying the willingness of European Member States to support and promote integrated governance policies for the administration and conservation of cultural heritage [2].

ICOMOS (International Council on Monuments and Sites) in the New Delhi Declaration [42] proposes an advancement in the interpretation of community participatory process, characterizing it with planning and operational aspects. Finally, identifying the continuity of "living heritage" [43] as a condition for sustainable development based on "a close relationship between nature, culture and people" [42], it opens up a new perspective on the two-way relationship between cultural heritage and communities: it is important to consider not only the value it has for a society and the extent to which it improves quality and living conditions, but above all, to understand how communities can play an active role in its protection and promotion. Heritage therefore becomes a dimension that encompasses and enables the comparison between the multiple cultural identities that characterize contemporary communities, favoring mediation between different points of view in view of a common interest.

In this sense, cultural heritage is a common good [6], because it is no longer a place of mere cultural enjoyment but the living space of the community $[1,44]$ and expression of the 
"glue values" [45] that belong to all members of the community [5]. The interpretation of cultural heritage as a common good implies the adoption of more innovative governance policies and solutions capable of grasping this complexity and responding to the changing needs of communities [20,46].

The following sections explore, through a case study analysis, whether and how the heritage community can play an active role in the conservation of local heritage as "common good" [3], going beyond the traditional concept of "private" and "public" goods and establishing a new "pact" of collaboration between diverse subject towards a shared vision for heritage-led urban regeneration.

\section{Materials and Methods}

The case study of Rufoli, in the city of Salerno (Italy) was analyzed to understand the potential role of a heritage community for minor cultural heritage recognition, adaptive reuse, conservation, and valorization, in an entrepreneurial "circular" perspective. The heritage community is not a "given" element, since in many cases, minor heritage is less known and hardly recognized as an important element of the urban landscape by citizens and local governments [41], and even private owners of heritage sites, laying in a state of abandonment or underuse. It is therefore important to first recognize the heritage as a cultural capital, identify its value and activate the relevant actors that can have a role in its valorization process, towards turning a "dead" place into a living heritage able to regenerate resources and generate positive impacts in the city/territory [28,47]. The circular economy perspective proposed in the Horizon 2020 CLIC project strengthens and enhances this process, identifying natural and cultural capital as the key element of urban regeneration. The adaptive reuse of cultural heritage can be the occasion to re-build social ties and civic responsibility towards the common good, while reducing the "waste" of natural and cultural resources.

This perspective has been implemented in Salerno, adopting an action research approach $[48,49]$, based on empirical direct experimentations conducted by researchers together with a small group of activists in the local community. It was useful to put "private troubles" [50] in a common research space in which ordinary people, together with other stakeholders, develop and strength the powers of reflective thought, discussion, decision, and action. The activation of a stakeholders' engagement process aimed at building a heritage community around a less known, but very relevant local cultural heritage: the ancient furnaces of clay tiles, a practice active since the Roman times in this area of the city. Starting from a phase of knowledge building and local stakeholders engagement, the research group activated processes of knowledge building, envisioning, and community engagement for the adaptive reuse of local cultural heritage inspired by the circular economy model. Figure 1 shows the interconnected phases of the methodological process.

It should be highlighted that the process is not linear nor planned in every detail since the start of the activities. The methodology is meant as a "learning-by-doing" process, in which needs and ambitions of engaged stakeholders are continuously tested and adjusted step by step, while results are periodically co-evaluated to re-orient action [51,52]. The enlargement of the initial group formed by local activists and researchers implies a revision and enlargement of the objectives and related planned activities. Next sections present the case study and the methods adopted in each phase of the process as explained in Figure 1.

\subsection{The Case Study of the Ancient Furnaces of "cotto" in Rufoli, Salerno}

Rufoli is an ancient borough located in the hilly area of Salerno (Figure 2), in the locality of Ogliara, which overlooks the gulf from the southeast. The territory is permeated with history, traditions, and ancient productions - cultural, productive and natural capital, tangible and intangible-which could potentially become the driver for a territorial, social, and cultural development. 


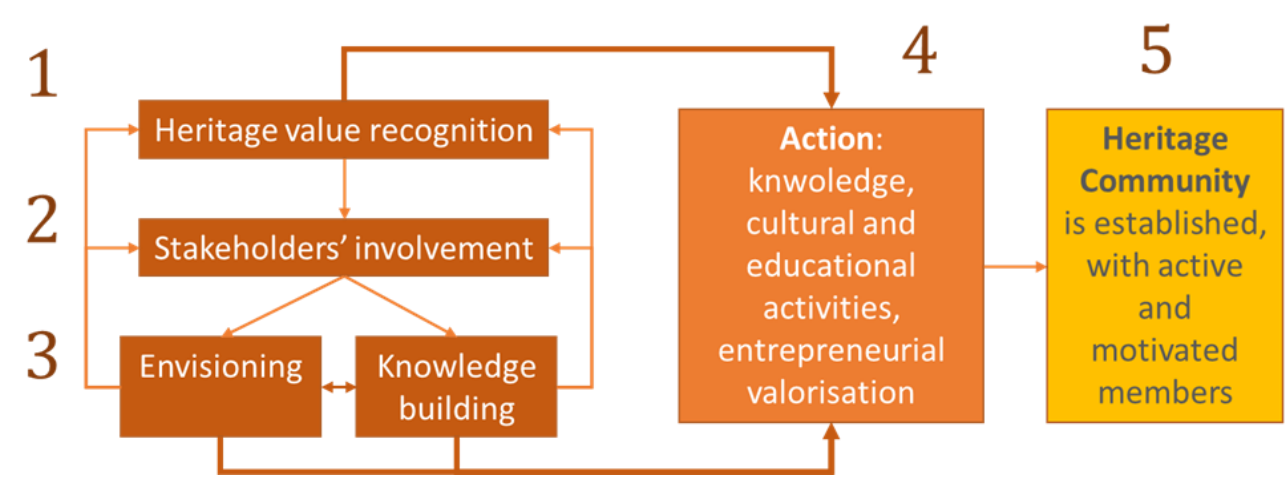

Figure 1. Interconnected phases of the methodological process. Source: elaboration of Antonia Gravagnuolo. Phase 1-The value of cultural heritage, tangible and intangible, is recognized through an action research approach based on empirical direct experimentations conducted by researchers together with a small group of activists in the local community; Phase 2-Activists and researchers start the stakeholders mapping exercise and engage key actors for the successive phases; Phase 3-A parallel exercise of envisioning and knowledge building is carried out: stakeholders collect existing knowledge in form of books, documents, pictures, evidence of traditions, oral testimonies; site visits are organized; Based on the knowledge collected, the stakeholders group co-developed a shared "vision" for the recovery and adaptive reuse of the heritage asset; this vision is tested through citizens engagement through an open questionnaire administered online and in site through stakeholders' network. The questionnaire was administered online in a period of one month between September and October 2020. It reached out directly 228 people who started to fill-in the online form, of which 143 (69\%) completed all questions to the end. Phase 4-The previous phases 1-3 contribute to reinforce the awareness on heritage values and the demand of cultural and circular activities linked to the heritage site, preparing the ground for actions development; Phase 5-The Heritage Community is established, with active and motivated members, to conserve and valorize cultural heritage through joined civic action and "circular" entrepreneurial activities.

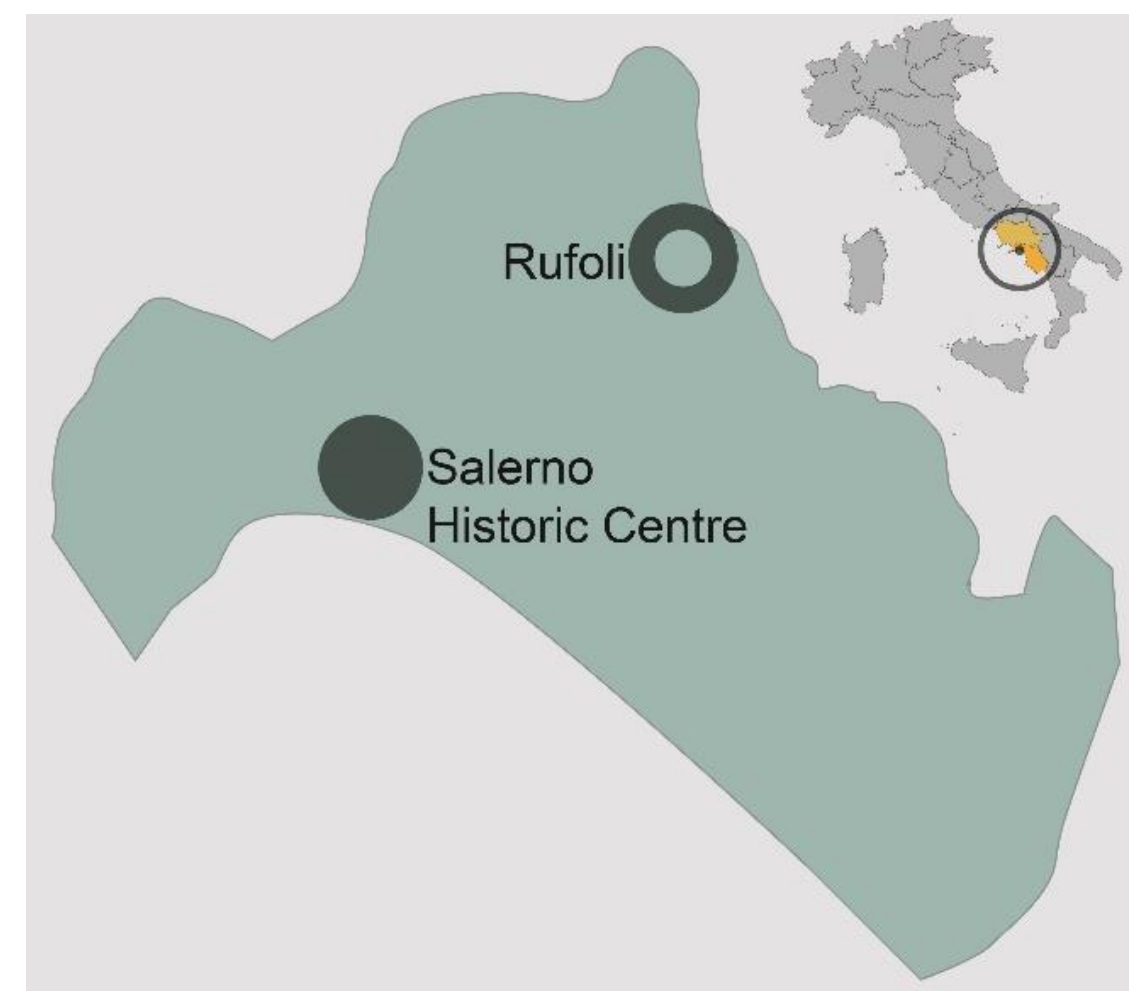

Figure 2. The case study area of Rufoli, in the urban periphery of Salerno, southern Italy. Source: elaboration by Serena Micheletti. 
The case study was selected as part of the experimentation of participative governance models for cultural heritage adaptive reuse in the city of Salerno, included as pilot city of the Horizon 2020 CLIC project which focuses on the adaptive reuse of abandoned and underused cultural heritage in a circular economy perspective.

Diverse activities were organized, such as stakeholders' meetings, conferences, peerreview meetings with other European cities representatives, workshops, in which the local community participated with enthusiasm. Stakeholders encouraged the activation of a permanent laboratory (Salerno Heritage Innovation Partnerships -HIPs Stakeholders' Permanent Lab) with weekly meetings to stimulate a more close collaboration both among the various stakeholders and with the Horizon 2020 project team, collecting, sharing, and analyzing proposals for the definition of a Local Action Plan for the adaptive reuse of cultural heritage in Salerno. In this context, several working groups were formed on specific interests of the stakeholders involved, including a working group for the valorization of the tangible and intangible cultural capital of Ogliara/Rufoli, particularly of the ancient furnaces for the production of traditional cotto (terracotta) tiles.

The main attribute of value of Rufoli site is the richness of excellent quality clay used for production activities, strongly linked to the territory, already used at the time by the Greek potters of Paestum, then used over the centuries for the production of bricks, tiles, pantiles, and tiles specific for the construction [53,54]. These activities have made the territory of Rufoli one of the most appreciated productive landscapes of the Salerno area since the middle age, in particular, for the presence of the above mentioned clay caves, watercourses, and the same terracotta furnaces that have been present for about one thousand years [55]. Traces of clay tiles production could date back even to the Roman times. The furnaces are all located along the same orographic relief of the clay hill for the availability of the raw material, but also for the proximity to the southern route of the Roman Empire's traffic from Capua to Reggio Calabria. In fact, these furnaces are part of a wider network that included, in the province of Salerno, other furnaces in Pontecagnano and Eboli, which have also enriched the territory with archaeological sites [53]. Historical insights on the themes of terracotta production, furnaces, and other territorial activities are documented and deepened by multiple local studies [56-62]. Among all of them, mainly in a state of abandonment, it is to underline the presence of two active furnaces for the production of terracotta of high manufacturing quality, Fornaci De Martino, also acting as catalysts for international artists. One of the two furnaces-whose owner is an active stakeholder of the working group of the Rufoli area-is used for the production and cooking of cotto, while the other is mainly used for workshops and educational purposes.

The cultural and natural capital of the area includes the archaeological, historicalartistic, architectural heritage such as the Medieval Church of San Martino and the Museum of Creative City, the natural heritage of watercourses, clay caves of Mandrizzo, the nearby "Montestella" Park, but also the intangible and demo-ethno-anthropological heritage with the history and traditions linked primarily to the different phases of production and cooking of the ancient furnaces. Intangible heritage includes also the traditional production of local cultivations from the autochthonous grape of "Sanginella", to local handicrafts, religious and secular festivals and rites, gastronomy, dialect and ancient sayings. In the past centuries the hilly area has facilitated the cultivation of autochthonous wines-with particular reference to the Sanginella grape, already known at the time of the Salerno Medical School; local associations are trying to recover it, in collaboration with the Municipality of Salerno, the Campania Region, and the Faculty of Agriculture of the University Federico II of Naples.

According to the UNESCO Historic Urban Landscape (HUL) Recommendation $[15,63]$, mapping and analysis of attributes and values of local heritage was conducted as the first step to reuse and regenerate cultural heritage.

The mapping and analysis process was initially conducted through focus groups. This led stakeholders to share knowledge and exchange views and ideas about the possible valorization of the interesting cultural heritage present in the area, which today looks as a 
quite anonymous "periphery" (Figure 3) even though some urban renewal projects have been developed by the Municipality in the last years.

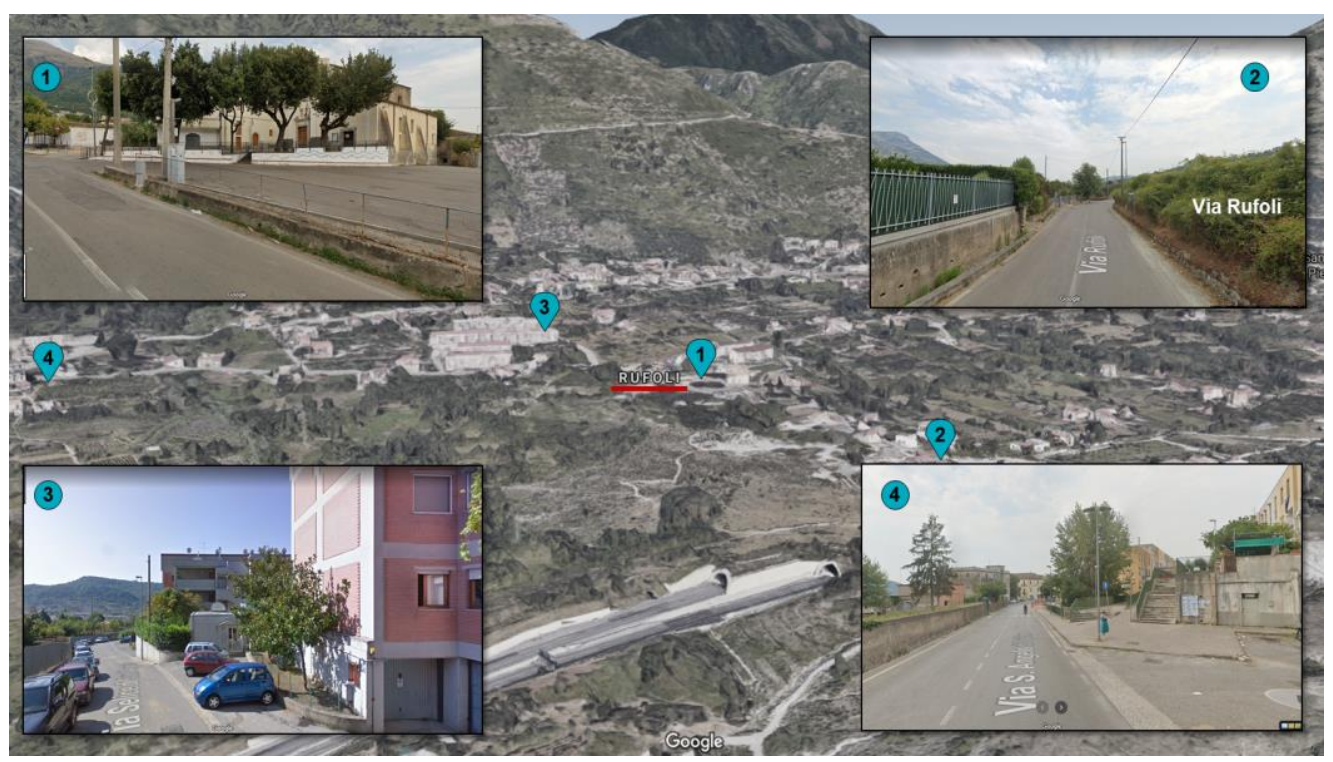

Figure 3. The peripheral urban area of Rufoli, Salerno: 1-Via Rufoli/San Michele Church; 2-Via Rufoli; 3-Via Selice di Sant'Angelo; 4-Via S. Angelo di Ogliara adjacent Museum of Creative City. Source: elaboration by Serena Micheletti. Source of pictures from Google Street view images.

\subsection{Stakeholders' Involvement: Building a Heritage Community}

A stakeholder analysis was carried out with the participation of the local activists and researchers in the initial phase, in order to identify the most relevant stakeholders that could have interest and decision-making "power" to carry out an action plan for the adaptive reuse of heritage resources in Rufoli.

Stakeholder Analysis is an organizational process of identification of all the individuals and internal teams that will be involved or influenced by a project. The term stakeholder is used as a general term to describe individuals, groups, or organizations that have an interest in the project and can mobilize resources to affect its outcome in some way [64]. A formal definition of a stakeholder is: "individuals and organizations who are actively involved in the project, or whose interests may be positively or negatively affected as a result of project execution or successful project completion" [65].

A stakeholder analysis usually takes place before the start of the project and is based on the elaboration of categories in which stakeholders are grouped according to their levels of participation, interest and influence in the project. This type of analysis includes all techniques or tools to identify and understand the needs and expectations of stakeholders both within the project and externally. The stakeholder map is, therefore, elaborated through an analysis of the context and its evolution over time [66]. Understanding attributes, interrelationships, interfaces between and between project supporters and opponents is indispensable for strategic project planning.

The steps to be taken before the start of a project for the implementation of a stakeholder analysis are:

1. Clarify who are the project stakeholders.

2. Understanding and aligning the expectations and individual impact that each stakeholder may have with the project objectives.

3. Outlining the processes of changing requirements; knowing that their needs (i.e., needs and expectations) are likely to change.

4. Linking needs and expectations with risk planning and risk response activities.

5. Conscientiously plan the communication strategies of the project. 
This information can then be monitored and modified as needed throughout the project in order to avoid that, focusing exclusively on the progress of the project, no attention is paid to the changing interests of the stakeholders involved. It is clear that understanding stakeholders' needs and expectations is crucial in defining the strategies that lead the project to success [65].

In Salerno, the initial brainstorming phase was developed during the Horizon 2020 CLIC project meetings. The approach adopted was that of the focus group which, although not very structured compared to other methods, is useful in building consensus among participants. This required strong facilitation and mediation skills on the part of the research team to make it effective and achieve good results [67].

During the CLIC meetings, some stakeholders showed affinities and common interests for the less-known heritage of Rufoli in Salerno. The more active stakeholders decided to join forces with researchers with the aim to re-activate the less known and abandoned heritage of Rufoli. Following a bottom-up approach, stakeholders were initially grouped as "activists" adopting the "reconstructive method" of stakeholder analysis suggested by Dryzek and Berejikian [68]. In fact, this method, through the participation of the main actors of the socio-ecological system in the study, analysis, and drafting of the results, allows a better view of the reality of the "arena" in which converging or opposing interests form alliances or create conflicts [69]. After this first brainstorming phase, subgroups of stakeholders were identified.

The "action arena" was first defined [31], i.e., the place where actors make choices, take decisions, develop their relationships. The arena of action represents the context in which stakeholders necessarily act (Figure 4). It is influenced by a set of three categories of variables:

1. Institutional factors: the set of rules or institutions that govern the arena.

2. Socio-cultural and economic factors: characteristics of the individual appropriators and of the community of reference, both economic (e.g., the degree of dependence of the users on the resource itself) and individual and cultural (mutual trust, the existence of shared values, and so on).

3. Physical factors: the environmental context, both natural and artificial, in which the actors move and against which their actions acquire a concrete meaning. The context interacts with the number of users and their capacity to consume the resource, determining the characteristics of exploitation [33].

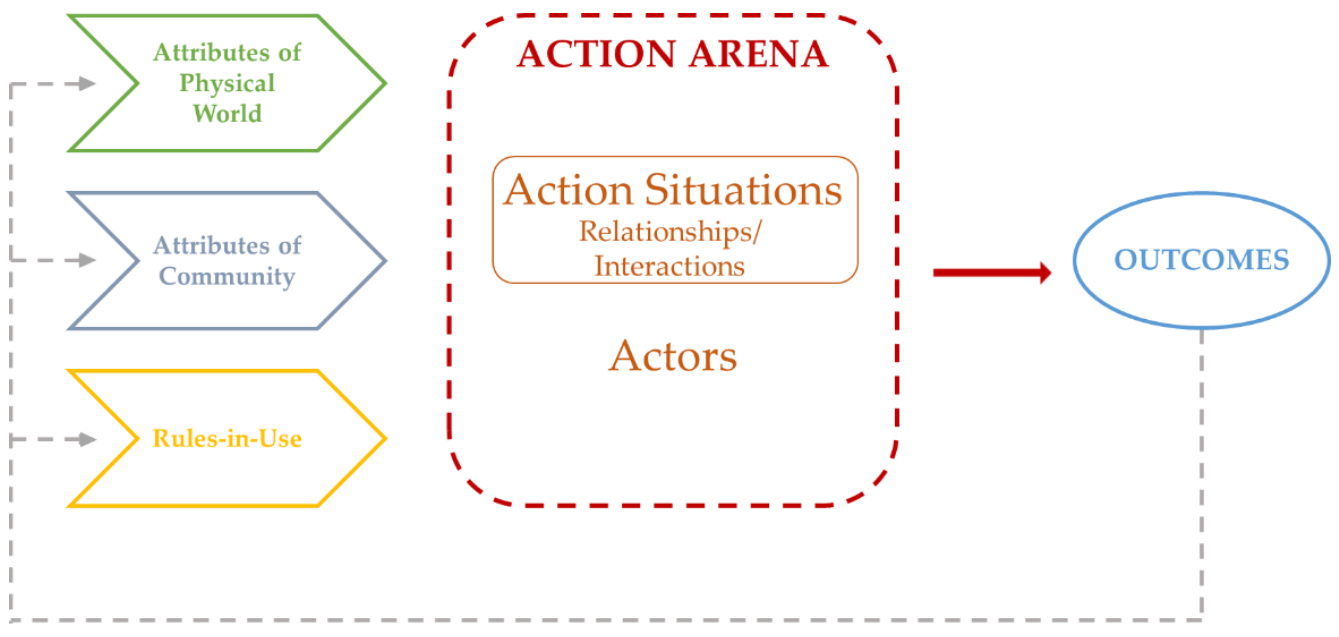

Figure 4. Definition of "action arena". Source: adapted by Ostrom et al. [31] (p. 37).

Stakeholders categories were grouped into macro-categories (Table 1): promoters, operators, and users. To the first group belong institutions and experts, those who have a high influence in choices geared towards the common good. The second group includes the 
operators, but also civil society organizations, i.e., those who have a high level of interest and medium influence (e.g., operators in the dominant economic sectors). Finally, the third group of users includes citizens and tourists/visitors, i.e., those who have a high level of interest but a low influence. This category is represented by subjects who do not have usually the means and the tools to be able to express their interests in a strong and homogeneous way, and coincide often with the target groups of public policies, to be involved in the formulation of the policies themselves.

Table 1. Stakeholders categorization.

\begin{tabular}{cc}
\hline Stakeholder Macro-Categories & Stakeholder Categories \\
\hline PROMOTERS & $\begin{array}{c}\text { Research institutions } \\
\text { Local Government } \\
\end{array}$ \\
$\begin{array}{cc}\text { Heritage Authorities } \\
\text { Education institutions }\end{array}$ \\
\hline OPERATORS & $\begin{array}{c}\text { Civil society organization } \\
\text { Enterprises }\end{array}$ \\
\hline USERS & Citizens \\
& Tourists/visitors \\
\hline
\end{tabular}

Stakeholders in all specific categories were involved in the process, as explained in the Results section.

\subsection{Heritage Mapping and Analysis}

The first brainstorming meetings with stakeholders led to the identification of relevant cultural and natural heritage in the area of Rufoli. A first mapping exercise focused on heritage attributes and values was conducted through 3 focus groups with 10 local activists and experts representing civil society organizations, research, professionals, and institutions. Appendix A summarizes the characteristics of the main cultural and natural heritage of the site, classifying it into "tangible cultural heritage", "intangible cultural heritage", and "natural heritage". Attributes (characteristics) of each heritage resource were described. Values were classified into "social-cultural", "environmental", "economic", and "intrinsic" [28,39,47,70-73].

The perceived importance of heritage conservation is linked to its "complex value", and particularly to the Total Economic Value component (TEV). The concept of TEV is widely acknowledged in economic valuation theory [74-78]. It includes two main components: the "use value", direct and indirect, and the "non-use value". Fusco Girard [39,70,71] introduced the notion of "Complex Social Value" (CSV) of cultural heritage, exploring also the existence of an "intrinsic value", a "value in itself", independent of any use/benefit perceived by people [28,71-73].

According to the CSV theory, an "intrinsic value" has also been identified for Rufoli's heritage resources, providing an initial and brief description. The state of conservation was briefly assessed. Results are reported in the Appendix A-Attributes and values of cultural and natural heritage in Rufoli, Salerno.

The perception of heritage values was then assessed through the questionnaire administered to the local community, which results are described in the following sections.

Between the cultural capital assets of the area, it should be also mentioned the "Museo Città Creativa" (Museum of the Creative City) located nearby the ancient furnaces. It can be classified as a both tangible and intangible cultural capital (modern structure). The Museum was launched by the Municipality of Salerno to enhance the local traditions of ceramics craft and provide a place for culture and education in the eastern periphery of Salerno. The Museum of the Creative City was meant as a cultural hub for the eastern part of the city of Salerno. Its cultural and social value is related to its mission as cultural institution. It has a landscape value as its architecture was designed to become a landmark 
in the area. Its economic value is linked to the cultural and educational activities carried out, and the creativity it could convey throughout the local community. However, this museum is currently underused, with few activities per year, and represented a focus of discussion for stakeholders, even if it was not included as cultural "heritage" of the area for its modern features.

Based on the initial analysis of heritage attributes and values, and according to the HUL approach, after mapping heritage (Figure 5), consensus among stakeholders was sought, connecting to an enlarged community to raise awareness and test the interest for the reuse and regeneration project. The following section describes the results of the stakeholders' engagement and consultation process.

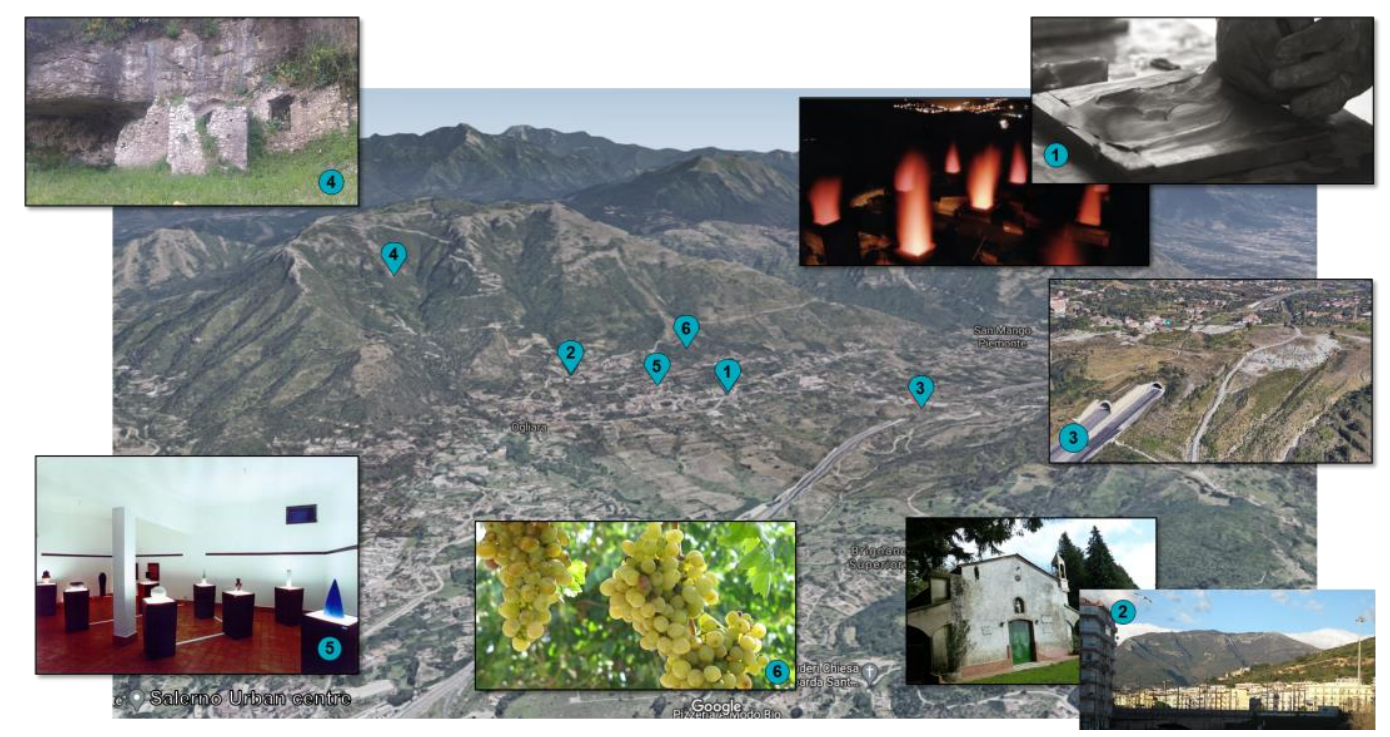

Figure 5. Rufoli area with focus on heritage assets mapped. Source: elaboration by Serena Micheletti. Source of pictures: 1-Fornaci De Martino and tradition of clay tiles making, Available online: https:/ / www.fornacedemartino.it (accessed on 19 April 2021); 2-Montestella Park and its religious heritage (Di Aleandro25-Opera propria, CC BY-SA 4.0, Di Raniero Supremo-Opera propria, CC BY-SA 4.0); 3-Mandrizzo Caves; 4-Archeological sites (Di Alexehilary-Opera propria, CC BY-SA 4.0); 5-Museum of Creative City, Available online: www.comune.salerno.it (accessed on 19 April 2021); 6-Sanginella grapes.

\subsection{Stakeholders' Analysis and Engagement Process}

After the first phase of heritage mapping and analysis, carried out through a focus group with 10 local activists and experts, additional stakeholders were identified and contacted through a "snowball" approach, starting from civic associations, professionals, and entrepreneurs already involved in the working group. The identified categories of stakeholders were actively engaged in the subsequent envisioning and knowledge building process. First of all, within the CLIC project, the research team ("research institution") and the municipality of Salerno ("local government") begin to dialogue and collaborate. Starting the participatory process, "enterprises", "civil society organizations", and "heritage authorities" were involved. In the "enterprises" category, local enterprises and enterprises associations are included. For the "civil society organizations" category, associations and local professional bodies were engaged who were already active in culture and cultural heritage valorization and in local sustainable development processes; for "heritage authorities", those who were active at the local and provincial level were considered. Then, stakeholders began to open up to the context and identified potential relationships and synergies with other categories: In particular, in order to expand the network and implement actions, "education institutions" were involved and active "citizens" autonomously have proponed themselves to be included in the activities of the project. 
Finally, stakeholders started self-organizing by involving other stakeholders in the elaboration and launch of further projects related to the main objective of the European project.

Figure 6 shows the progressive development of the stakeholders' network, highlighting with continuous lines those stakeholders that have been directly involved by the project, while with dashed lines, those that have been identified as only "potential".

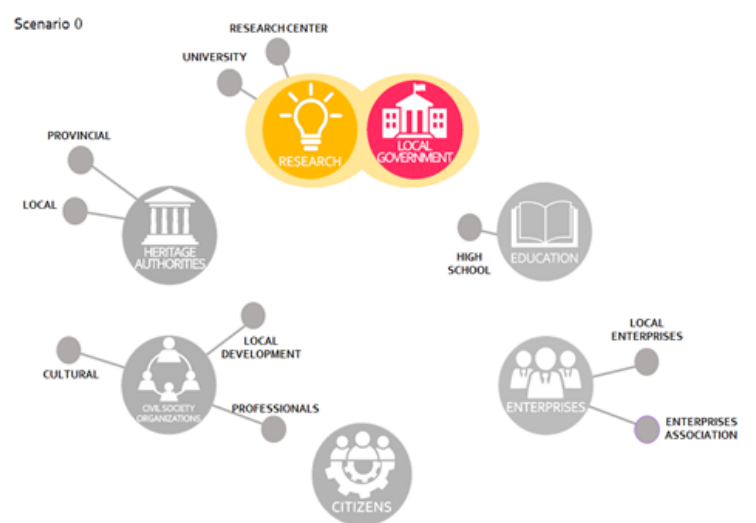

(a)

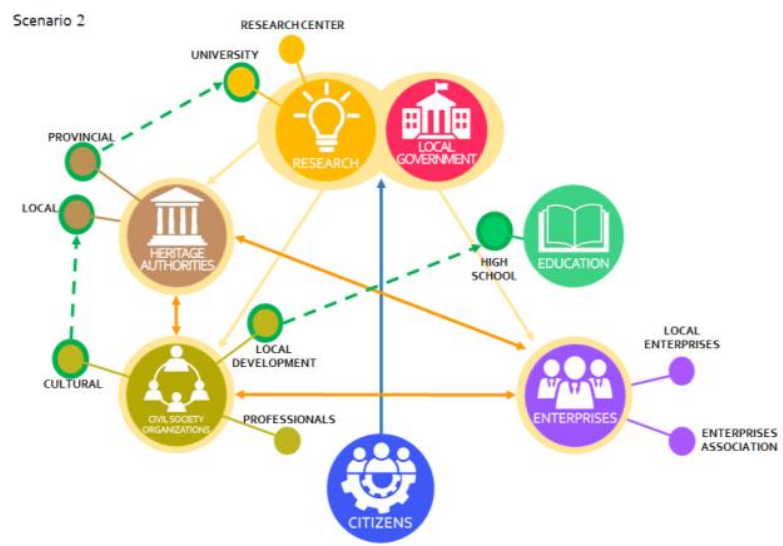

(c)

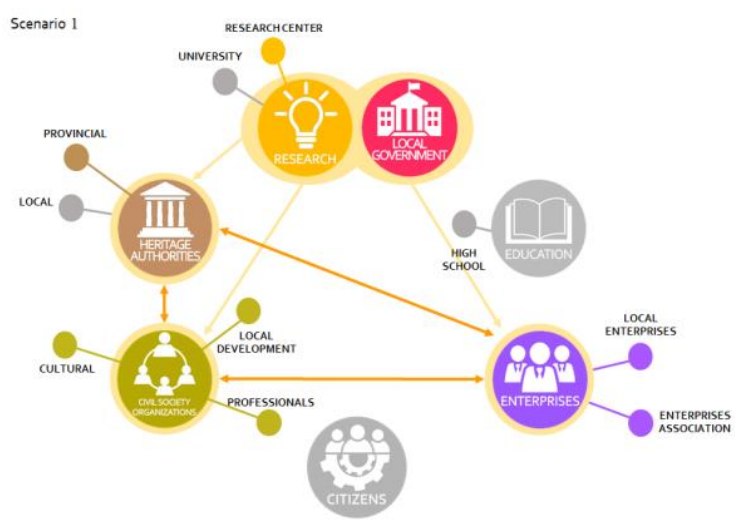

(b)

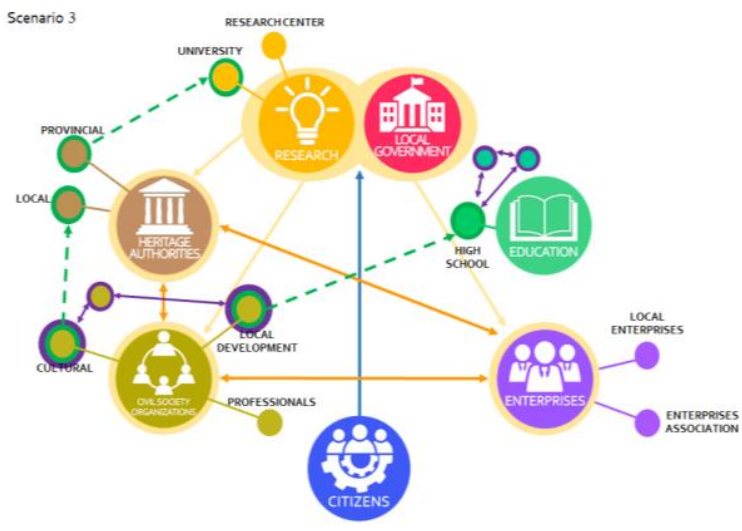

(d)

Figure 6. Process of stakeholders' network building: (a) Scenario 0; (b) Scenario 1; (c) Scenario 2; (d) Scenario 3. (a) Scenario 0: Each of the stakeholders in the city was used to carry out its activity independently. Within the CLIC project, the research team and the municipality of Salerno begin to dialogue and collaborate; (b) Scenario 1: CLIC participatory process for the Local Action Plan on cultural heritage adaptive reuse started, engaging local stakeholders. Initially, businesses, civil society organizations, and heritage authorities were involved. Thanks to the stakeholders meetings, workshops, and events, the stakeholders involved started to dialogue and interact; (c) Scenario 2: Stakeholders began to open up to the context and identified potential relationships and synergies, in order to expand the network and implement actions; (d) Scenario 3: Stakeholders started self-organizing by involving other stakeholders in the elaboration and launch of further projects related to the main objective of the European project. Source: elaboration by Martina Bosone.

The intensity of relationships increased throughout the process, which was conducted in a period of one year between 2019 and 2020 and it is currently ongoing. The process was slightly slowed down by the COVID-19 outbreak, however meetings continued remotely, using digital tools. Stakeholders demonstrated high interest and active participation in all meetings, conducted every two weeks. The result was the sharing of knowledge, strengthening of collaboration and cooperation relationships, and the shared "vision" codeveloped. The initiative started to raise awareness at the local level, demonstrated by local journal articles and more attention demonstrated by public administrators for a site that was quite neglected as a "periphery". A careful analysis of the impacts of this process on 
social networks density and awareness for cultural heritage should be carried out, however this will need a larger timespan since the start of the process (at least 2-3 years to assess actual impacts).

\subsection{Towards a Shared Vision for Heritage Reuse and Regeneration: Results of the Envisioning Phase}

After the assessment of heritage values and the enlargement of the stakeholders' base in the working group, three focus groups were carried out to discuss alternatives of action to reuse and regenerate Rufoli heritage.

The general objective of the working group, made of civic activists and researchers, was declared as to identify effective actions to safeguard cultural heritage, raise awareness, increase respect for diversity, promote mutual understanding and cooperation, and contribute to the sustainable development of the communities involved in a circular economy perspective, according to the Horizon 2020 CLIC approach.

Specifically, the working group identified the need of building synergies between businesses, citizens, and public bodies in order to regenerate local cultural and natural values and contribute to new job opportunities through a circular economy approach. The circular economy was highlighted as a regenerative development model, where no wastes are generated and local human, natural, and cultural resources are valorized as drivers of long term growth and new jobs, improving well-being and health of citizens, the urban landscape, and public spaces. The conditions for a new attractiveness of the peripheral area of Rufoli are thus created, for innovative and creative businesses, residents, and tourists/visitors.

Based on the activity of listening of the territory and cooperation towards a strategic vision, it was imagined that Ogliara di Rufoli could become a place aimed at experimentation, research, artistic production and dissemination on the topics of the "New City" [58], and environmental regeneration; the experience of the ancient furnaces already recovered could be the driver that continuously stimulates new reflections. To this purpose, the working group - together with the stakeholders -envisioned some actions to be taken for the enhancement of the territory, also through the reuse of abandoned sites, thinking specifically the ex-Furnaces to the production of cotto.

The actions foreseen were synthesizes as:

- reactivation of the ancient furnaces in state of abandonment for new circular production processes;

- experiential visits to the ancient furnaces, enhancing the history and value of this tradition;

- heritage walks to re-discover the history and rich heritage of Rufoli area;

- digitalization of the heritage and knowledge collected, using website and social media channels to engage a wider public;

- in-depth historic studies and research on Rufoli's heritage;

- urban art installations focused on cotto making and ceramics;

- educational activities in collaboration with the Museum of the Creative City;

- cleansing and enhancement of green areas;

- enhancement of pedestrian walkability of the Rufoli neighborhoods;

- $\quad$ other (to be specified, open to suggestions of participants).

The vision, synthesized through the actions foreseen, was then tested through the questionnaire administered to the local community.

\subsection{Envisioning, Knowledge Building, Knowledge Sharing, and Awareness Raising}

Following the focus group method, a series of 3 meetings were dedicated to sharing ideas and visions for the future development of the Rufoli area, and specifically about the reuse and regeneration of local cultural heritage. The vision synthesized the point of view of all stakeholders. Researchers acted as moderators to facilitate open discussion, share and synthesize knowledge, and manage conflict. 
The envisioning exercise resulted in a series of possible actions to enhance cultural heritage. The interest and priority level of the actions foreseen were tested through a questionnaire administered to the local community. The questionnaire aimed at assessing the level of knowledge of the cultural capital of Rufoli between community members and beyond the boundaries of the city of Salerno, as well as the interest in reusing the abandoned heritage resources, allowing participatory collection and management of community-based data and testing of the vision co-developed by the working group. The questionnaire was co-developed and administered by the working group members, supported by researchers. It was designed to ensure the greatest possible inclusion, through questions that can be understandable to all age and social groups, with different lifestyles, background, and education.

The questionnaire was structured as follows:

A. Introduction/welcome page: brief presentation describing the context and the objectives of the questionnaire;

B. Informed consent form (required to participate);

C. Section 1-knowledge of the cotto tradition: assessment of the level of knowledge of the ancient furnaces of Rufoli and the cotto tradition;

D. Section 2-significance of the tradition and the production of cotto for the community: assessment of citizens' perception about the value of this cultural heritage in Rufoli and the importance perceived about its conservation and enhancement;

E. Section 3-prioritization of actions: priorities assessment related to a set of suggested actions for the enhancement of cultural heritage in Rufoli; reflections and suggestions for the elaboration of development scenarios for the area of interest; willingness of citizens to be involved in workshops on extensive cultural heritage mapping;

F. Demographics: age, level of education, profession, place of residency.

The questionnaire was part of a wider framework of knowledge and mapping of cultural capital, conducted in the first year of the CLIC project (started in 2018), which also includes mapping workshops and the elaboration of collaborative geo-referenced maps (e.g., using OpenStreetMap).

The questionnaire was elaborated through the Survey Monkey platform and administered online. The rich stakeholders network, strengthened due to the activation of Salerno HIPs Stakeholders' Permanent Lab in October 2019 and still ongoing, has allowed a rapid and huge dissemination of the questionnaire. The questionnaire was spread through associations communications, social media, WhatsApp groups, email, and word of mouth. The schools taking part in the working group informed the teachers and included the questionnaire also on their official web pages, thus including families and students. Moreover, press articles about the activities carried out in Rufoli with the related link to the questionnaires were published in the local newspapers, printed and online.

\section{Results}

\subsection{Rufoli Heritage Assessment Questionnaire}

The questionnaire of cultural capital and cultural heritage assessment in the Rufoli area was administered online in a period of one month between September and October 2020.

The questionnaire was organized using binary questions, multiple-choice questions, open-ended questions, and Likert-scale option questions.

The binary questions were used to test the knowledge level of the cotto tradition and the ancient furnaces of Rufoli/Ogliara and to assess the interest in participating in a workshop for mapping the cultural and natural capital of the Rufoli/Ogliara area.

A single multiple-choice question was formulated to establish a priority ranking among the proposals considered most effective by the respondents for the enhancement of the heritage of Rufoli/Ogliara.

A single open-ended question was formulated to get a suggestion from the respondents on possible improvement actions or a greater attention to a place of their particular interest Rufoli/Ogliara. 


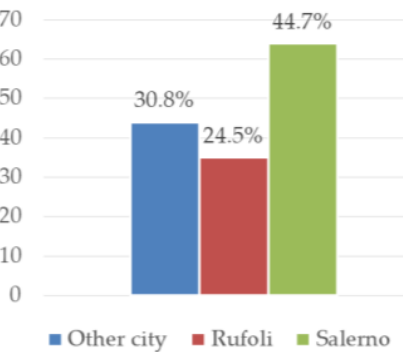

- Other city - Rufoli = Salerno

(a) Residency

Likert-scale option questions were used both to test the respondents' level of awareness about the importance of enhancing the tangible and intangible cultural heritage of Rufoli/Ogliara, with particular reference to the tradition of cotto making in the ancient furnaces, and to know their interest in deepening their knowledge about the place. In the Likert-scale option questions, a 5-point scale was used, in which score 1 corresponds to "not at all", score 2 to "a little", score 3 to "quite a lot", score 4 to "important", and score 5 to "very important".

The questionnaire reached out directly 228 people who started to fill-in the online form, of which 143 completed all questions to the end. The results were analyzed only for the 143 complete answers, of which 99 residents in Salerno (69\%) and 44 non-residents $(31 \%)$. The first phase of the analysis was the observation and "cleaning" of raw data through text analysis of open answers. The sample was diversified in terms of residency, age, and educational qualification.

Participants were mostly from other neighborhoods of Salerno (44.8\%) and $\mathrm{Ru}-$ foli neighborhood $(24.5 \%)$. The $30.8 \%$ were residents in other cities outside of Salerno, (Figure 7a). Most participants were in the age range between 30-50 years (46\%), while a large number were above 50 years old $(38 \%)$ and young participants resulted in the lowest age range (16\%) (Figure $7 \mathrm{~b})$. Regarding the educational qualification, participants with post-degree professional qualification resulted as the largest group (46\%), followed by participants with Secondary school level (32\%), Bachelor's degree level (10\%), Primary school level (8\%), university specialization (8\%), and PhD level (6\%) (Figure 7c).

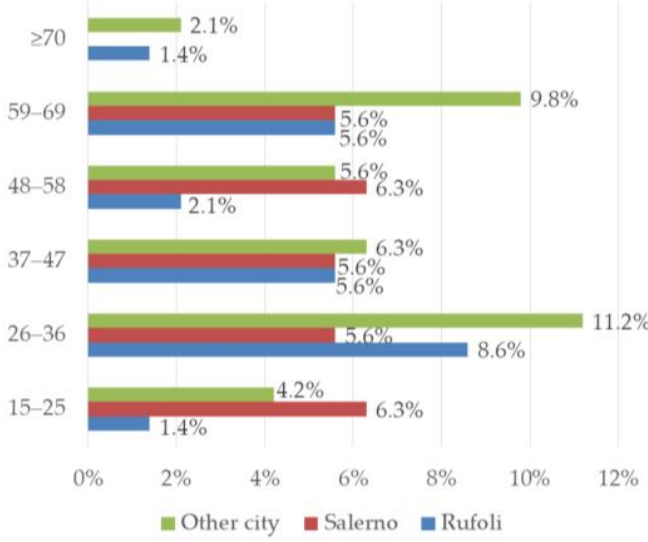

(b) Age

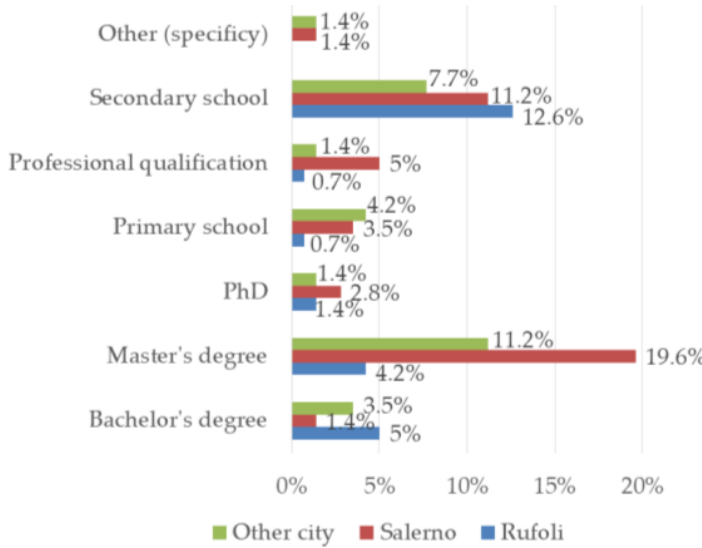

(c) Educational qualification

Figure 7. Results of the questionnaire on cultural heritage in Rufoli-descriptive statistics on demographic data: (a) residency, (b) age and education, and (c) qualification of participants linked with their residency place. Source: elaboration of the authors.

Furthermore, standard deviation of age group both for all respondents and for respondents group divided by residency was calculated. Table 2 shows that the average age for all groups is about 44 years and the standard deviation is about 15 .

Table 2. Standard deviation of age group both for all respondents and for respondents group divided by residency.

\begin{tabular}{cccc}
\hline & Count & Average & Standard Deviation \\
\hline All Respondents & 143 & 44.2 & 15.5 \\
Rufoli & 35 & 43.6 & 15.8 \\
Salerno & 64 & 44.1 & 15.5 \\
Other City & 44 & 44.0 & 15.6 \\
\hline
\end{tabular}


The following figures aim to highlight differences between the three groups of respondents. All the above aspects were analyzed considering three main variables: the respondents' place of origin (Rufoli, Salerno, and other city), their age group (six age groups were identified: $15-25,26-36,37-47,48-58,59-69, \geq 70$ ), and their educational qualifications (Bachelor's degree, Master's degree, Ph.D., Primary school, Professional qualification, Secondary school, or Other).

The choice of analyzing the data according to these three variables aims to understand the relationship between the answers and the demographic characteristics of the sample of respondents.

First of all, it was analyzed whether respondents know the local cultural heritage (with particular reference to the furnaces and the cotto tradition). The $60 \%$ ( 87 respondents out of 143) declared to know about the tradition of cotto making in Rufoli and the ancient furnaces. Of these respondents, as expected, the residents in Salerno and Rufoli represented a majority (respectively $43 \%$ and $37 \%$ ) (Figure 8 ).

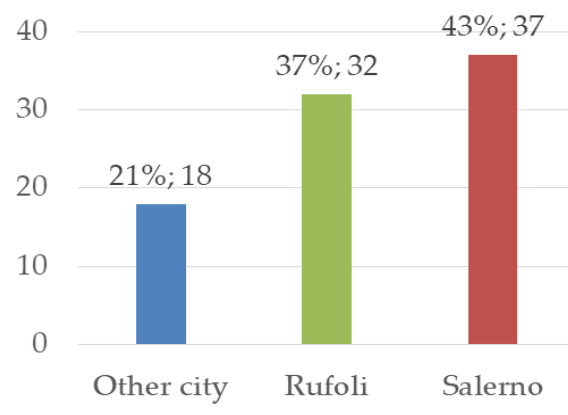

Figure 8. Knowledge about the tradition of cotto for residents and non-residents-subset of 87 respondents who declared to already know. Source: elaboration of the authors.

Starting from the analysis of these data, the answers related to the knowledge of the local cultural heritage (with particular reference to the furnaces and the cotto tradition) (Figure 9), the interest to "learning more" about history and traditions of cotto (Figures 9 and 10), and the consequent interest to be involved in participating in a workshop to map the cultural and natural capital of the Rufoli/Ogliara area were analyzed (Figures 11 and 12). Finally, the evaluation of the respondents' average awareness on the importance of conserving cultural heritage values of ancient furnaces and of cotto tradition (Figures 13 and 14) and the prioritization of actions to implement the strategic vision for Rufoli heritage adaptive reuse and valorization (Figures 15-18) have been useful and were used as a starting point for the definition of a shared vision for heritage reuse and regeneration.

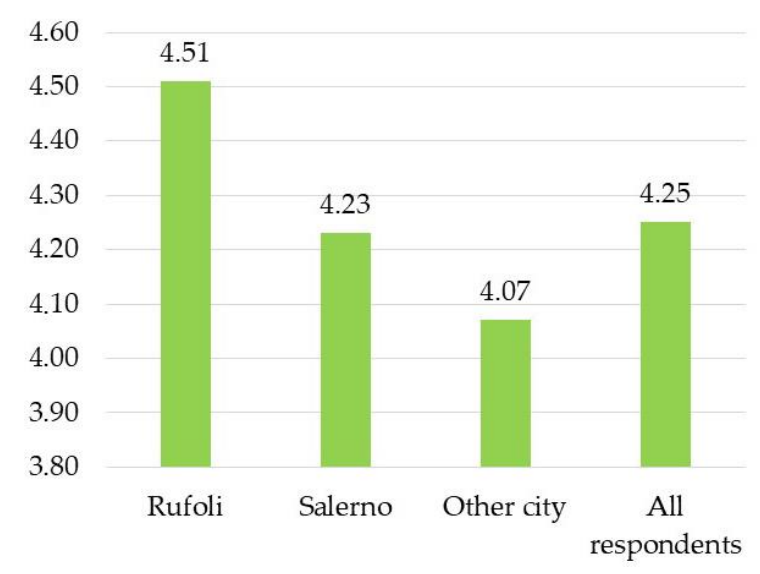

Figure 9. Average interest to "learning more" about history and traditions of cotto, in a scale from 1 (low) to 5 (high). Source: elaboration of the authors. 


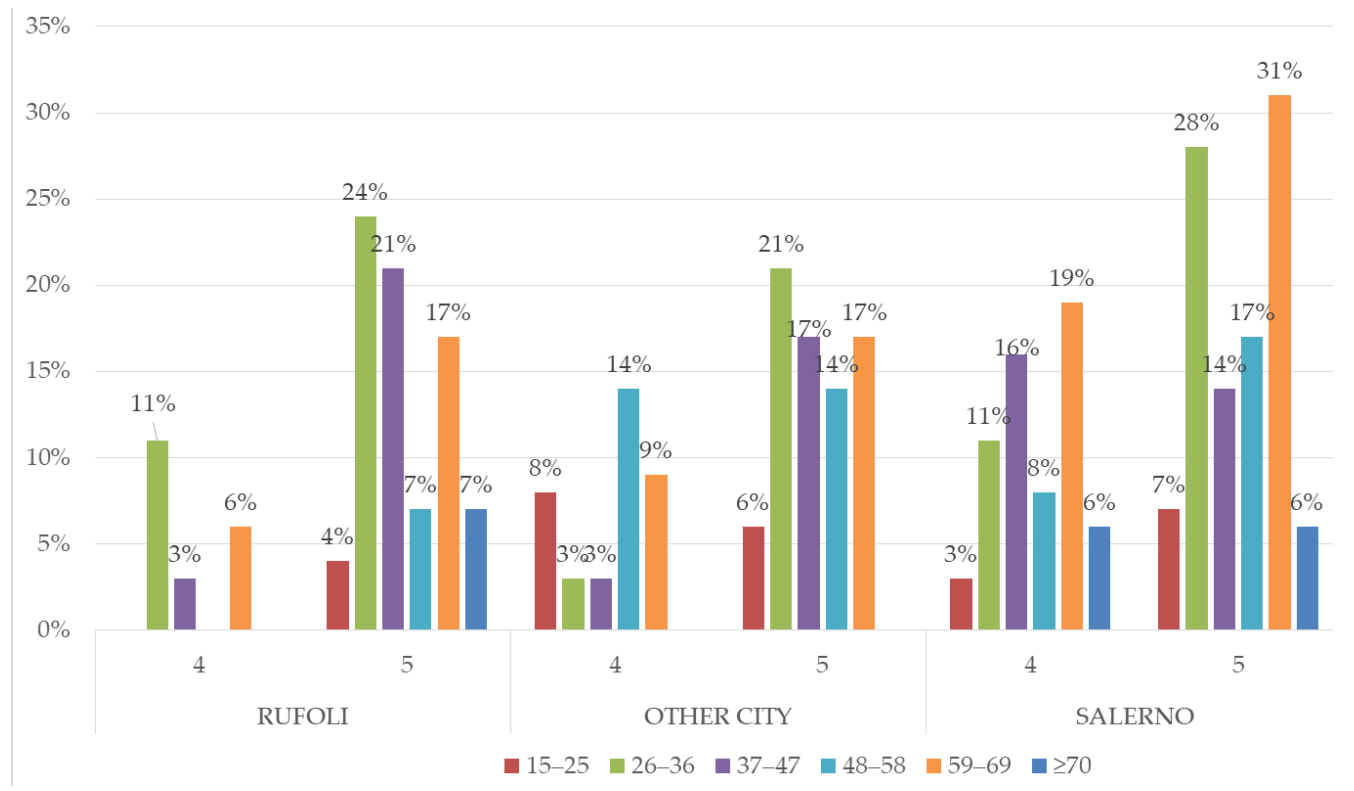

(a) Age

$60 \%$

$50 \%$

$40 \%$

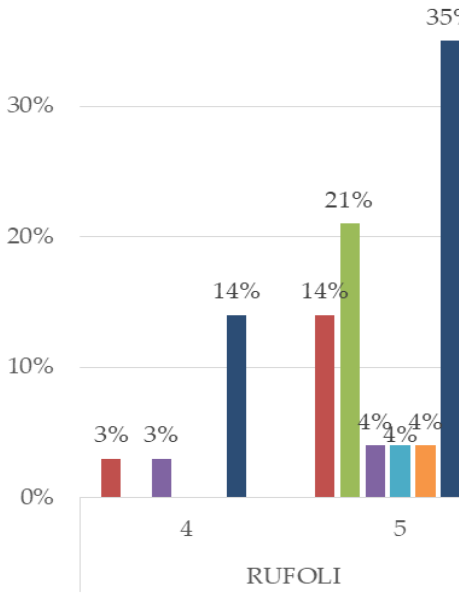

- Bachelor's degree

- Professional qualification
Master's degree

ndary school
$56 \%$

(b) Educational qualification

Figure 10. Awareness by age (a) and by educational qualification (b) of Rufoli's, Salerno's, and other city's respondents on their interest in learning more about the history and cotto tradition. Source: elaboration of the authors. 


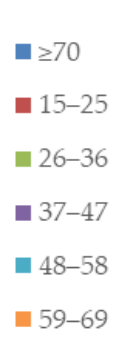

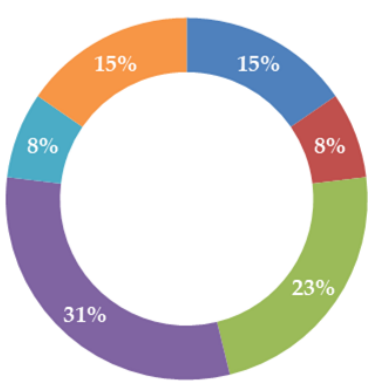

(a)

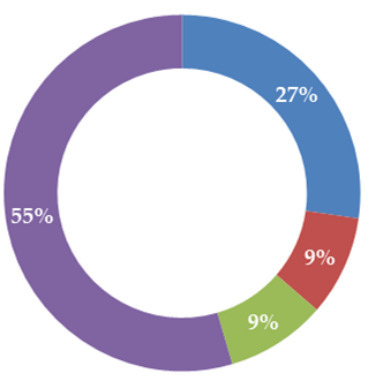

(b)

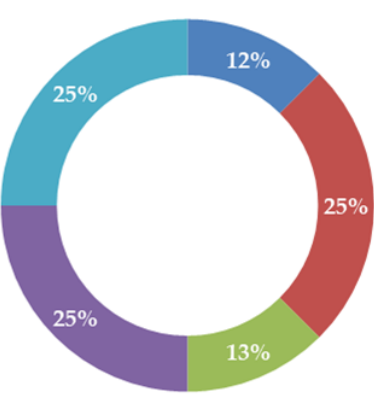

(c)

Figure 11. Age classification of Rufoli's (a), Salerno's (b) and other city's (c) respondents interested in participating in a workshop to map the cultural and natural capital of the Rufoli/Ogliara area. Source: elaboration of the authors.

\footnotetext{
- Other (specificy)

- Bachelor's degree

- Master's degree

- $\mathrm{PhD}$

- Primary school

- Professional qualification

- Secondary school
}

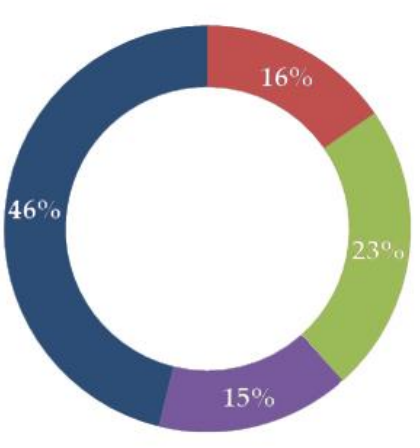

(a)

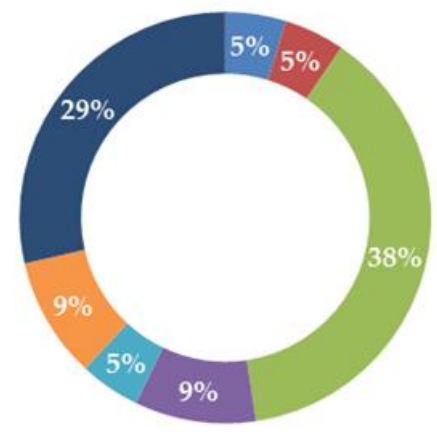

(b)

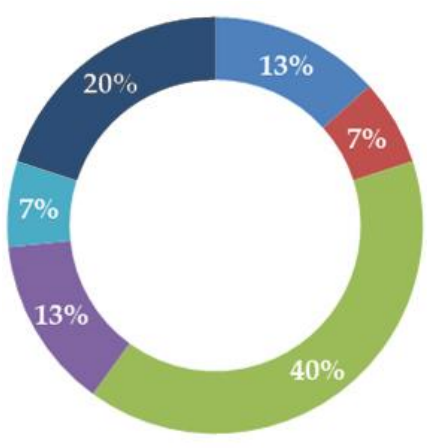

(c)

Figure 12. Educational qualification of respondents from Rufoli (a), Salerno (b), and other city (c) interested in participating in a workshop to map the cultural and natural capital of the Rufoli/Ogliara area. Source: elaboration of the authors.

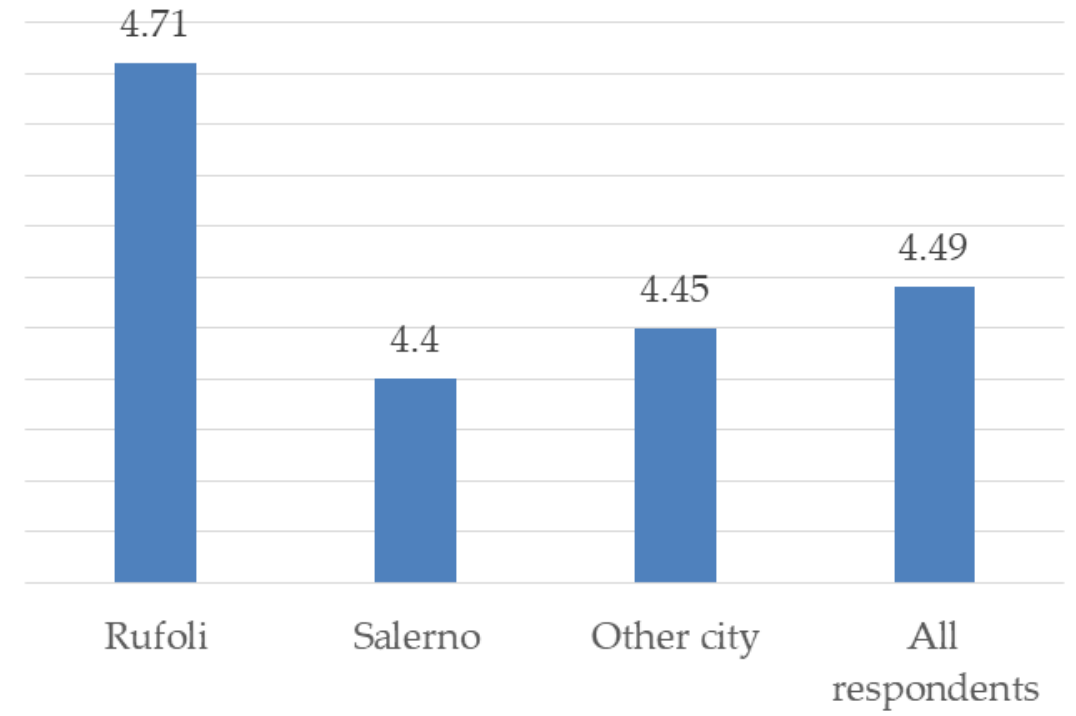

Figure 13. Average awareness on the importance of conserving cultural heritage values of ancient furnaces and cotto tradition, in a scale from 1 (low) to 5 (high). Source: elaboration of the authors. 


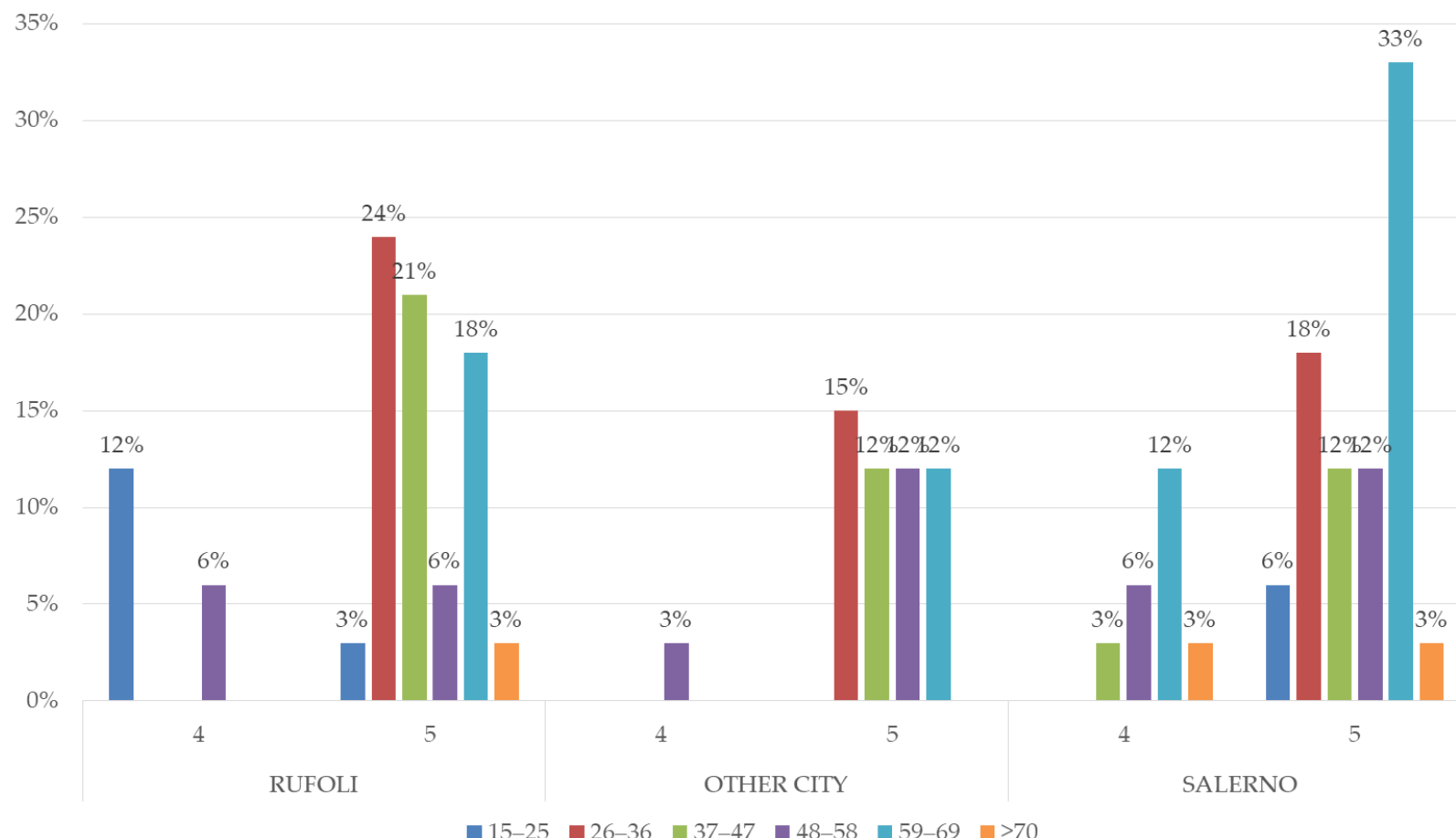

(a) Age

$60 \%$

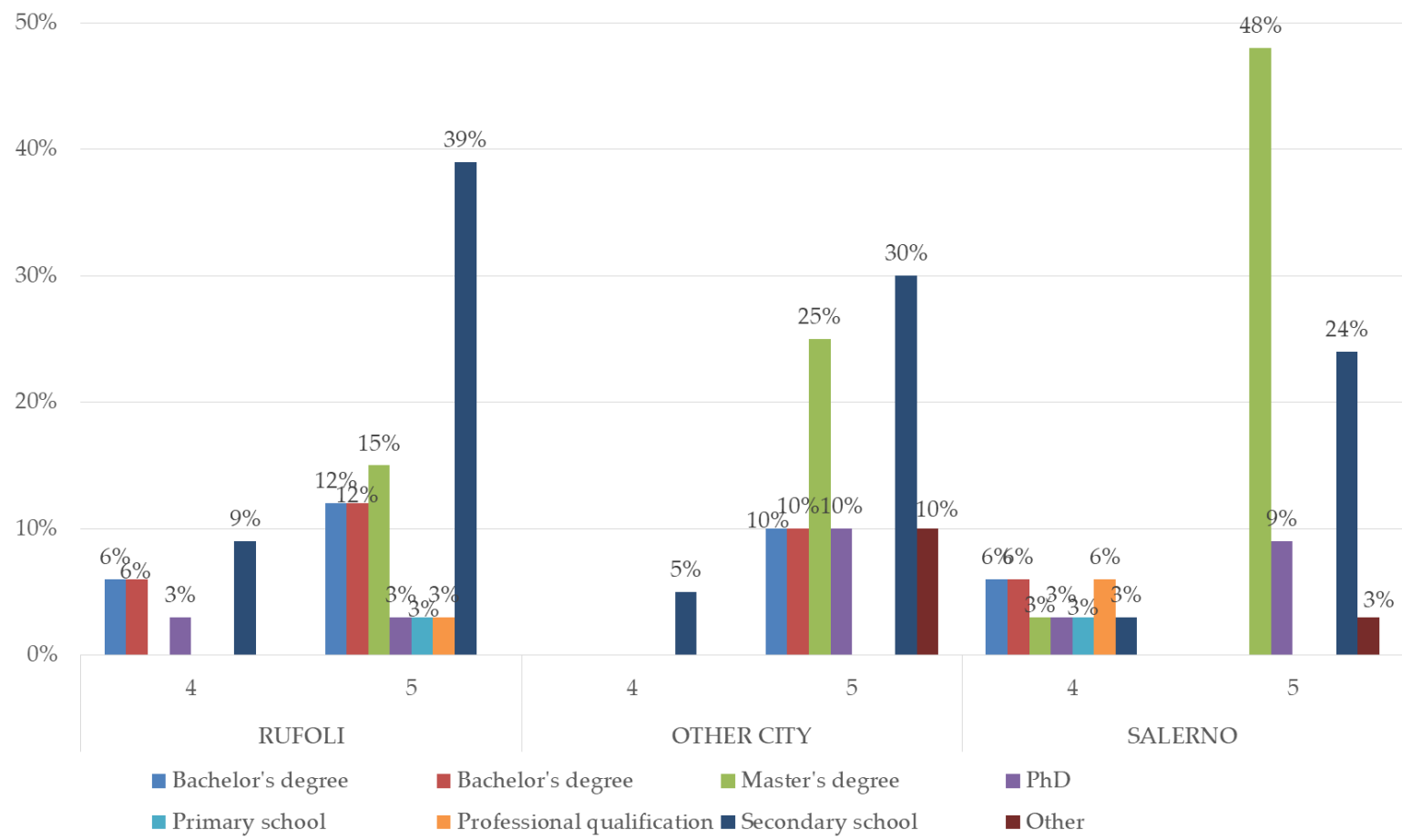

(b) Educational qualification

Figure 14. Average awareness by age (a) and educational qualification (b) of respondents from Rufoli, Salerno, and other cities on the importance of conserving cultural heritage values of ancient furnaces and of cotto tradition. Source: elaboration of the authors. 
experiential visits to the ancient furnaces, enhancing the history. reactivation of the ancient furnaces in state of abandonment for. educational activities in collaboration with the Museum of the.

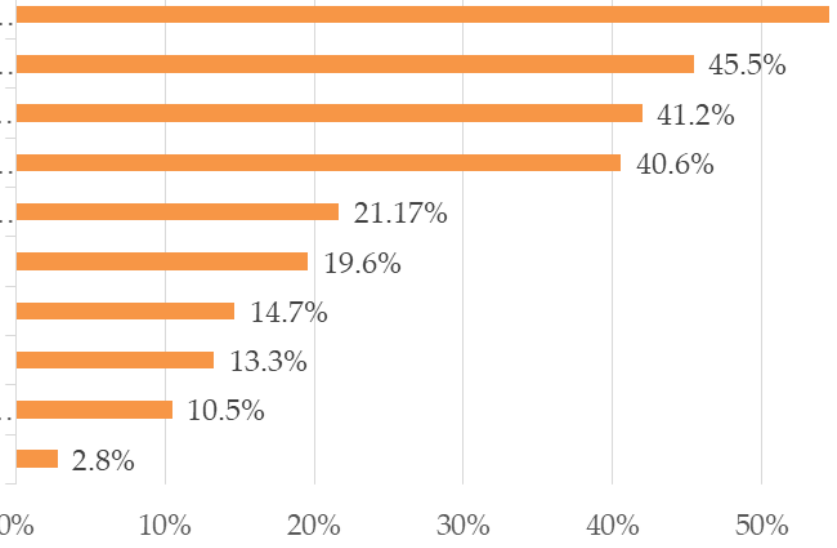
heritage walks to re-discover the history and rich heritage of. digitalisation of the heritage and knowledge collected, using. cleansing and enhancement of green areas; urban art installations focused on cotto making and ceramics; in-depth historic studies and researches on Rufoli's heritage; enhancement of pedestrian walkability of the Rufoli. other (to be specified, open to suggestions of participants) $0 \%$ $10 \%$ $20 \%$ $30 \%$ $60 \%$

Figure 15. Prioritization of actions to implement the strategic vision for Rufoli heritage adaptive reuse and valorization—All respondents. Source: elaboration of the authors.

All respondents (143)

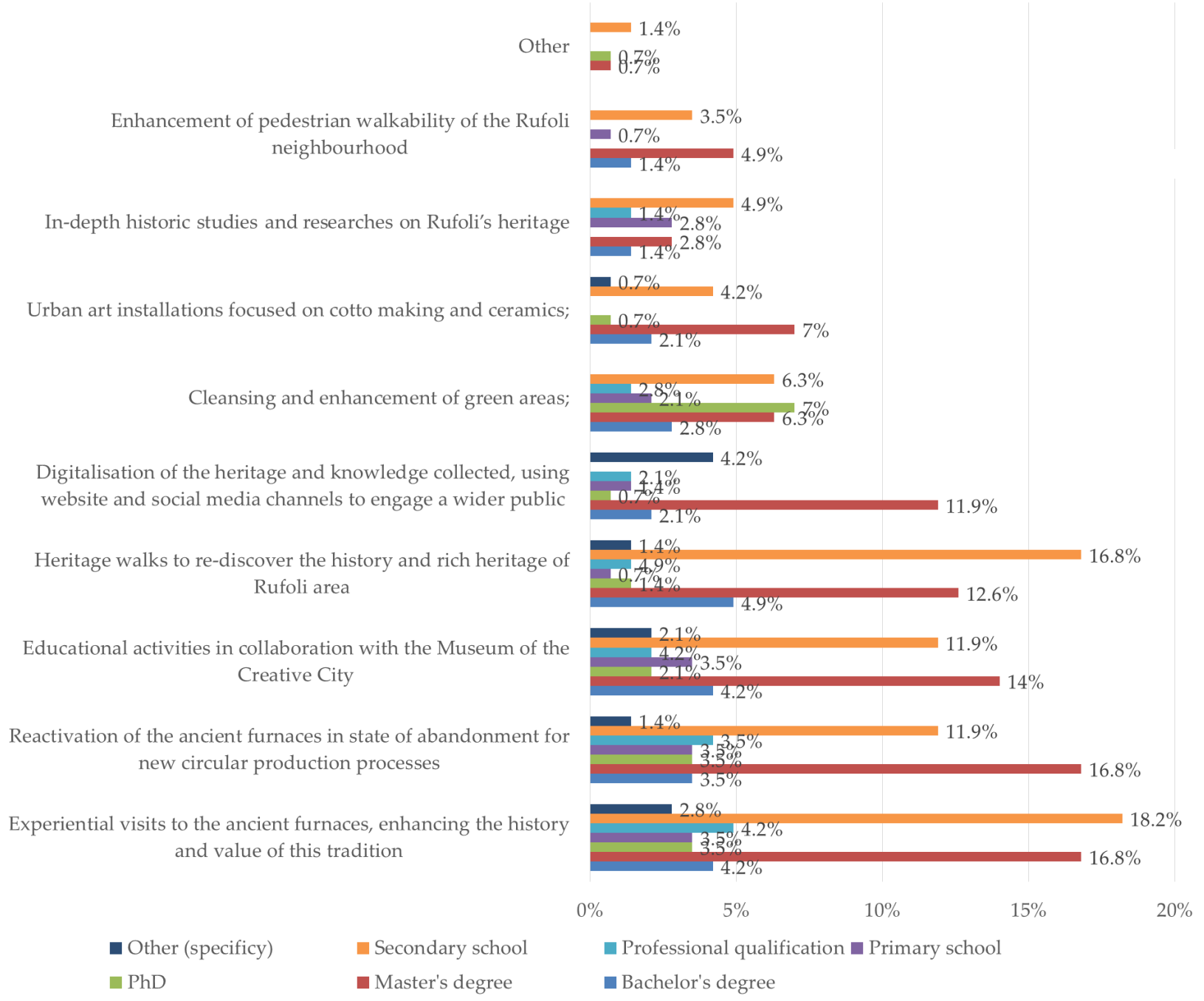

Figure 16. Prioritization of actions by educational qualification of respondents to implement the strategic vision for Rufoli heritage adaptive reuse and valorization-All respondents. Source: elaboration of the authors. 
Residents in other cities (44)

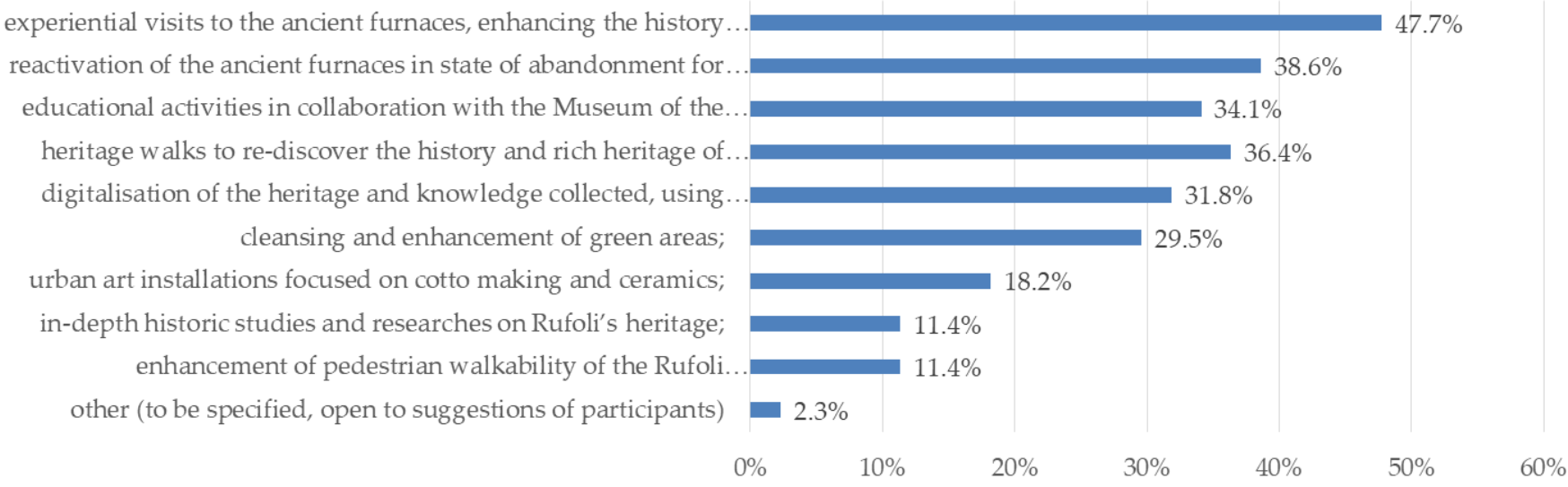

Figure 17. Prioritization of actions to implement the strategic vision-Residents in other cities. Source: elaboration of the authors.

\section{Residents in Salerno (99)}

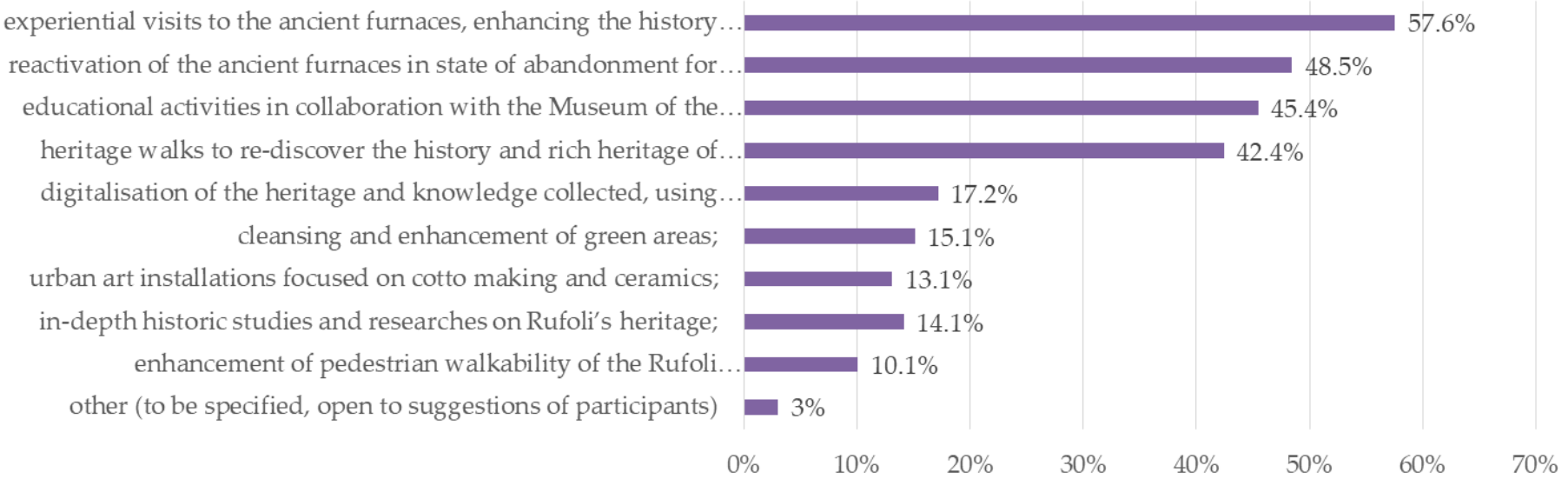

Figure 18. Prioritization of actions to implement the strategic vision-Residents in Salerno. Source: elaboration of the authors.

All respondents were asked whether they would be interested in "learning more" about the history and traditions of cotto making in Rufoli. The average score was above 4 for all respondents, while Rufoli residents' scores were higher in average, as it could be expected (Figure 9).

Figure 10 shows the average awareness by age (a) and by educational qualification (b) of Rufoli's, Salerno's, and other city's respondents on their interest in learning more about the history and cotto tradition.

In both cases, the figures highlight the differences between those who responded by assigning a score of 4 ("important") or 5 ("very important") both because for these two scores, the number of respondents was higher than the other scores and there were differences among the answers.

In the first case, (a) the majority of respondents from Rufoli and other city are between 26 and 36 years old ( $24 \%$ and $21 \%$, respectively). In Salerno, the same age category represents $28 \%$, while the majority is made up of respondents between 59 and 69 years old $(31 \%)$.

In the second case, (b) the figure highlights the differences between those who responded by assigning a score of 4 ("important") or 5 ("very important"), categorizing them according to the city they come from. As it can be seen from the graph, in all three cases, 
the majority of respondents gave the highest score to this aspect and corresponds to people whose highest qualification is a Master's degree or Secondary school. Among these, in Rufoli's respondents, there is a clear prevalence of people with a Secondary school category $(35 \%)$ compared to those with a Master's degree $(21 \%)$, whereas for respondents from other cities and Salerno, this trend changes. Considering respondents from other city there is no significant difference between the Master's degree average score $(24 \%)$ and Secondary school average score $(17 \%)$, while considering respondents from Salerno this difference is much more evident as the percentage of respondents with a Master's degree $(56 \%)$ prevails over those with a Secondary school (35\%).

Another important question was related to the interest of respondents in participating in a workshop for mapping the cultural and natural capital of Rufoli/Ogliara.

Figure 11 shows that in Rufoli (a), the majority of people most interested in participating in a workshop for mapping the cultural and natural capital of Rufoli/Ogliara are between 37 and 47 years old (31\%), while they represent only $13 \%$ of respondents living in Salerno (b) and 9\% among respondents not living in Salerno (c). In fact, in Salerno (b), the majority of those most interested are aged between 59 and 69 (55\%) while for those who do not live in Salerno (c), there is parity for the $15-25,37-47$, and $48-58$ age groups.

With respect to the same question, considering the educational qualification (Figure 12), in Rufoli (a), the majority (46\%) has as highest educational qualification the Secondary school, while in Salerno (b), the percentage of people with this qualification $(29 \%)$ is second to those with a Master's degree (38\%). The same dynamic can be found for respondents from other cities (c) where the percentage of people with a Master's degree is $40 \%$ while those with a Secondary school represent $20 \%$.

Residents in other neighborhoods of Salerno and in other cities demonstrated a similar level of awareness of cultural heritage values, which could suggest the presence of an "indirect use value" linked to the possibility of learning about the heritage resources of the territory and thus receiving and indirect benefit from it. In addition, it could be recognized a "non-use value", linked to the pure interest for the conservation of this heritage as a resource for present and future generations.

The importance of conserving cultural heritage values related to the ancient furnaces and the tradition of cotto making was also perceived as "highly important": the average scores for the Rufoli's respondents (4.71) overcomes the average score of all respondents which was above 4.50 (on a 1-5 Likert scale) (Figure 13).

Figure 14 shows the average awareness by age (a) and by educational qualification (b) of Rufoli's, Salerno's, and other city's respondents on the importance of conserving cultural heritage values of ancient furnaces and of cotto tradition.

As above, in both cases, the figures highlight the differences between those who responded by assigning a score of 4 ("important") or 5 ("very important") both because for these two scores the number of respondents was higher than the other scores and there were major significant differences among the answers.

In the first case (a), the majority of respondents from Rufoli and other city are between 26 and 36 years old (24\% and 15\% respectively). In Salerno, the same age category represents $18 \%$ while the majority is made up of respondents between 59 and 69 years old $(33 \%)$.

In the second case (b), the figure highlights the differences between those who responded by assigning a score of 4 ("important") or 5 ("very important"), categorizing them according to the city they come from. As can be seen from the graph, in all three cases, the majority of respondents give the highest score to this aspect and corresponds to people whose highest qualification is a Master's degree or Secondary school. Among these, in Rufoli's respondents, there is a clear prevalence of people with a Secondary school category $(39 \%)$ compared to those with a Master's degree $(15 \%)$. The same aspect characterizes also the sample of respondents from other city but the difference between the two categories is less evident (the category Secondary school represents 30\%, while the Master's degree one is $25 \%$ ). Considering respondents from Salerno, this trend changes and the difference 
between the Master's degree average score and Secondary school average score is much more evident as the percentage of respondents with a Master's degree $(48 \%)$ prevails over those with a Secondary school $(24 \%)$.

Finally, the questionnaire included a section on the prioritization of actions to implement the strategic vision for the adaptive reuse of cultural heritage in Rufoli (Figure 15), in the perspective of the circular economy model. A list of 10 actions was proposed, based on the envisioning process results, of which 3 of them were related to a general enhancement of the urban area, such as enhancement of pedestrian walkability, green areas, and urban art. Respondents were asked to select the most relevant 3 actions, with the possibility of including additional suggestions. The 143 respondents selected the action related to "experiential visits to the ancient furnaces, enhancing the history and value of this tradition" as the most relevant, with $54.5 \%$ of the total share. The actions on "reactivation of the ancient furnaces in state of abandonment for new circular production processes" $(45.5 \%)$, "educational activities in collaboration with the Museum of the Creative City" $(42.0 \%)$, and "heritage walks to re-discover the history and rich heritage of Rufoli area" $(40.6 \%)$ were selected as the most effective ones for the reuse, conservation, and valorization of cultural heritage in Rufoli, from the point of view of respondents.

Moreover, the figure shows that among those who preferred these three actions, the highest percentage is represented by respondents who have a Master's degree or Secondary school as a qualification. In particular, for the Master's degree category, they expressed a preference, especially for the action "reactivation of the ancient furnaces in state of abandonment for new circular production processes" $(16.8 \%)$, while for the secondary school category, the preference was for the action "heritage walks to re-discover the history and rich heritage of Rufoli area" (16.8\%) (Figure 16).

Few additional actions were proposed (2.80\%), which showed an overall coherence between the strategic vision co-developed by stakeholders and the "sentiment" of the local community. Four open answers were given with suggestions about additional actions to be realized in the site: "promote the eno-gastronomic local products", "promote the neighborhood as a 'historic' place", "organize site-specific cultural events", and "organize specialized training courses for cotto making, exploiting the currently active furnaces". It was also proposed a "pop up store" to make known the touristic and entrepreneurial offer in the area.

The four most relevant actions were selected by both residents and non-residents in Salerno. Analyzing more in-depth the answers of the two groups, it can be highlighted a higher preference of non-residents for the digitalization aspect including the creation of a website and social media channels (Figure 17), which could be related to the higher difficulty in enjoying the heritage in place due to physical distance. The COVID-19 outbreak could have enhanced this aspect, since visits in place and cultural activities were forbidden for many months during 2020.

It can be also noted that cleansing and enhancement of green areas, as well as urban art installations were perceived as more important for citizens outside Salerno (Figure 17), probably indicating that the area is perceived as a "anonymous" periphery, rather than a cultural site. On the other side, residents in Salerno and Rufoli (Figure 18) gave stronger emphasis to the reactivation of furnaces, educational activities, heritage walks, and experiential visits, showing awareness and clear interest in the regeneration of this important cultural heritage of Salerno.

The data analysis shown above stimulates significant reflections on the involvement of communities in the processes of re-use and regeneration of cultural heritage. In fact, the questionnaires show that citizens are increasing their proactive attitude towards the processes of protection, valorization, and regeneration of cultural heritage. Indeed, starting from an increased awareness of the importance of preserving cultural heritage (in terms of both material and immaterial values), they express interest and willingness to improve their own level of knowledge of their cultural heritage and of the possible tools to ensure its protection, valorization, and regeneration. This aspect translates both in the interest to 
be involved in culture-led activities (i.e., workshops, heritage walks, educational activities, etc.) based on the co-production and sharing of values and knowledge.

\subsection{Towards an Action Plan for the Adaptive Reuse of Cultural Heritage in Rufoli}

All phases of the work were important to shed light on diverse aspects of cultural heritage adaptive reuse, conservation, and regeneration. The questionnaire showed a substantial interest of the local community, both in the Rufoli neighborhood and in Salerno, as well as outside the city boundaries. This represents a potential demand for cultural, educational, experiential activities to be organized for the conservation and valorization of cultural heritage. The presence of a large group of stakeholders in this initial phase showed an interesting potential to build a heritage community able to take care of cultural heritage and develop valorization activities, reaching out to the local community and contributing to enhance citizens' civic responsibility.

The elements of local identity were recognized and systematized as drivers of sustainable development for the area of Rufoli. According to the results of the focus groups and the questionnaire, identity elements such as the furnaces and cotto production, the Città Creativa Museum or MonteStella park proved to be essential for the urban regeneration of this peripheral area.

The most relevant actions selected to promote the territory were related to the awareness raising, aimed at making the community conscious, by activating the interest of local actors (citizens, companies, institutions), in line with the FC. Heritage Walks have been imagined to describe the history and uniqueness of Rufoli sites, as well as the productive traditions still preserved. The activation of the walks can be planned in different ways, on the short and medium-long term, for the latter imagining widespread visits that also include museums related to the topic of ceramics spread throughout the province. For walks to be made in the short term, the focus is on the area of the furnaces, which includes both reused and abandoned sites, integrating them into a valorization circuit. The only furnaces in reuse (Fornaci De Martino) allows the realization of experiential and educational activities showing the whole process-always the same for centuries-from the extraction of raw materials in the clay caves to the production of terracotta. A series of events are currently planned to be realized for different target groups of visitors using the method of "design for all" for a wide sensorial and physical accessibility, with an inclusive approach that takes into account exhibitions and workshop events also for people with special needs. The action involves the collaboration of companies and associations, furnace owners, scholars, artists, and innovators, in order to build a "Heritage Community" [1,79].

To realize educational activities, a network of local schools is being created for the promotion of social training. It is intended as a process of development, of permanent modification of the vision of the territory and the actions on it, for the promotion of the sense of identity of the local community, extending this concept to the whole area of Salerno. Activities on the topic of cotto making, ceramics, and history of the place should be part of the annual and three-year school plans.

In a strategic planning, training and awareness raising, knowledge, and dissemination activities are expected to be parallel and sometimes converging in common activities (workshops, exhibitions, etc.). It is also hypothesized to activate courses within the active furnaces for the transmission of knowledge in this sector, contributing to the training of qualified professional figures.

The Museum of Creative City is envisaged in a wider scenario as a potential resource for territorial revitalization through integration in the valorization process. It is suggested, for example, that site-specific interventions or educational and awareness-raising activities could be organized in the long-term period to trigger feelings of belonging to the local area.

All these activities are included in the action plan that the local community is codeveloping for the area. An institutional and legal framework should still be identified, however the plan of the Municipality to activate a "Regulation for the shared management of cultural heritage as common good", under the Horizon 2020 CLIC project, could be an 
ideal opportunity for strengthening synergies between public, private, and social actors in the city.

\section{Discussion}

The aspects described in the previous section are also common to other experiments carried out in some of the involved CLIC partner cities/regions. Although they were supported by the use of different methods and tools than those used in Rufoli, the results obtained are in line with those of the experimentation presented in this paper. Below we report some of the most significant data regarding the experiences carried out by the research group of the Delft University of Technology in the cities of Amsterdam (Netherlands) and Rijeka (Croatia) and by the ICHEC Brussels Management School in the cities of Rijeka and Salerno and in the region of Västra Götaland (Sweden).

The Eindhoven University of Technology in 2018 organized a "HUL workshop" in the city of Amsterdam in which, using an investigation framework based on the six steps of the HUL approach (Mapping, Consensus, Vulnerability, Integrate, Prioritize, Partnership) and adapting to it the World Café method [80], it was possible to organize multi-stakeholders dialogues answering questions to harvest and build the collective knowledge (40 participants involved from public, private, and civic sectors, and 6 facilitators) [81]. The dialogue with the participants and the subsequent qualitative dataset analysis carried out by the research team made it possible to identify expressed challenges and solutions in the processes of adaptive reuse of cultural heritage. The results of the research conducted in Amsterdam is comparable to the result of this research, as also in that case the research team assessed that the proactive involvement of local stakeholders has an educational function not only because it improves knowledge of their cultural heritage but also because it positively influences their willingness to adopt collaborative attitudes to operationalize a medium- to long-term vision. This process of co-production of knowledge and collective knowledge contributes to strengthening the stakeholders' awareness of their self-organizing capacities and the importance of their role in decision-making processes. In particular, the research group highlighted that a progressive familiarity with the themes of reuse, regeneration, and participatory governance increases the stakeholders' capacity to approach the problem by proposing more operational solutions linked to the need to elaborate guidelines and identify innovative models of business and financing.

In the case of participatory action planning in Rijeka, conducted within the CLIC project, the main issues that emerged from the discussion with the stakeholders involved focused on themes related to participation, capacity, regulatory systems, economics-finance, and knowledge, highlighting the need to adopt a systemic approach coupled with a multiscale perspective in addressing the challenges to the adaptive reuse of cultural heritage [82].

Finally, the participatory mapping experiments carried out by the ICHEC Brussels Management School in the cities of Rijeka and Salerno and in the region of Västra Götaland (Sweden) led to the elaboration of "Maps of Landscape Perceptions". In this experimentation, the map was used by the research team as a participatory tool to both analyze the status quo and support the co-design of future strategies in order to reach consensus between the mapped perceptions of citizens and the expert-oriented description of the potential cultural resources of a city [83]. The use of perceptions mapping as a sense making process [84] demonstrates that "conservation is a dynamic process, as perceptions change over time, that helps to regenerate and re-connect tangible and intangible heritage assets in urban areas within a sustainable development framework aimed at human centered cities and regions".

Despite the variety and diversity of methods and tools used, current research underlines the importance of adopting an inclusive and integrated approach to the elaboration of strategies for the regeneration of cultural heritage, capable of providing a real response to the needs expressed at local level.

In conclusion, the results of this paper should be interpreted as first experimental insights on the potential role and activities of a heritage community for circular adaptive 
reuse of cultural heritage, based on a specific case study. A careful evaluation of impacts can be realized in the medium-long term, however the results of the questionnaire with regard to the interest and awareness of the local community are encouraging to continue the experimentation. Comparison with other heritage communities can be of high interest and usefulness, including also the use of the heritage community self-assessment tool proposed by the Council of Europe and further developed by [85], which aims at assessing the level of commitment, action and inclusion of the communities.

\section{Conclusions}

This paper developed and tested a methodology for collaborative adaptive reuse of cultural heritage, adopting a circular economy perspective, through an action research approach developed within the Horizon 2020 project CLIC. The main results obtained are summarized:

- In line with the HUL recommendation and the FC, the process included mapping cultural and natural heritage, recognizing diverse components of its complex value, and engaging the local community in collaborative actions for the adaptive reuse and regeneration of abandoned assets, activating informal and formal partnerships within a Heritage Community.

- Results of the mapping exercise, stakeholders' engagement, and envisioning showed a proactive attitude of stakeholders, aiming at enlarging the heritage community and reaching out to citizens and institutions to co-develop a shared vision for the future of cultural and natural heritage of Rufoli in Salerno.

- A set of actions related to education, training, experiential visits, and re-activation of productive processes adopting circular and sustainable production and consumption models resulted widely acceptable and desirable. This implied the recognition of a "hidden" cultural demand from citizens and potential end-users, which can represent a robust base for the development of heritage-led entrepreneurial activities. The "entrepreneurial ecosystem" includes not only companies in a specific territory, but also knowledge providers such as university and research entities, financing bodies, local governments, large companies as "drivers" of growth for smaller start-up, and the entire community which can play a key role in demanding and co-creating cultureled opportunities for jobs, entertainment, education, and training.

- The questionnaire administered had a double result of both collecting data on the level of knowledge, interest, and agreement with respect to the strategic vision for the site of Rufoli, and informing and engaging the local community in a wider collective action. The results of the questionnaire showed an unexpected level of interest within the local community, which would encourage further action through a bottom-up approach. However, it should be also considered the role of private and public owners of heritage sites, which could feel "attacked" by groups of active citizens contesting abandonment and underuse of heritage resources. This kind of conflict between active communities and legal owners of heritage sites could hinder the potential for effective conservation action. Therefore, careful attention to dialogue and cooperation of all relevant actors should be given since the start of reuse and regeneration actions.

The circular economy model for the adaptive reuse of abandoned heritage resources was introduced within the CLIC project and further developed through group reflections for the specific case of Rufoli. The ancient process of raw materials extraction and processing in the same site was considered an expression of the pre-industrial circular model, which is still active today and could be inspirational for new circular business models. Moreover, the reuse of every waste from the production process was considered an essential aspect of new activities to be carried out for the valorization of the ancient production techniques. The circular economy/circular city model implies also the re-naturalization of cities and the regeneration of the natural capital, which was a substantial part of the strategic vision for the Rufoli urban area. Another aspect was related to the enhancement of human capital, that would need additional resources in the medium-long term, through education, 
training, and cultural activities to enhance skills, capacities, and the "cultural" attitude to circularity. In fact, the "culture" of circularity plays a fundamental role in developing circular models able to regenerate natural, cultural, human, and social capital. Finally, the capacity and attitude for cooperation, collaboration, synergies, and symbioses building represent a "soft" element that can determine the success of new circular models in heritage reuse and regeneration processes. Therefore, the creation of a heritage community, as a "scope" community, could support the implementation of circular adaptive reuse of cultural heritage, focusing on cooperation models that foster territorial synergies.

Author Contributions: Conceptualization, A.G.; methodology, A.G.; questionnaire structuring and administration: A.G., S.M. and M.B.; data curation, A.G. and M.B.; writing-original draft preparation, A.G., S.M., M.B.; article organization and structuring: A.G.; supervision, A.G.; project administration, A.G.; funding acquisition, A.G. The authors have equally contributed to the development of this paper. However, the following sections have been written by: Sections 1, 2, 2.3 and 5 were written by A.G.; Sections 1.1, 2.2 and 2.4 were written by M.B.; Section 3.1 was written by A.G. and M.B.; Sections 2.1, 2.5, 2.6 and 3.2 were written by S.M. All authors have read and agreed to the published version of the manuscript.

Funding: This research was funded under the framework of Horizon 2020 research project CLIC: Circular models Leveraging Investments in Cultural heritage adaptive reuse. This project has received funding from the European Union's Horizon 2020 research and innovation program under Grant Agreement No. 776758.

Institutional Review Board Statement: Not applicable.

Informed Consent Statement: Not applicable.

Data Availability Statement: No new data were created or analysed in this study. Data sharing is not applicable to this article.

Acknowledgments: We gratefully acknowledge the contribution of the working group organizations and individuals who participated to all phases of the research. We also acknowledge the contribution of the Municipality of Salerno in co-organizing Heritage Innovation Partnerships meetings within the Horizon 2020 CLIC project and supporting the Permanent Laboratory for the circular adaptive reuse of cultural heritage in Salerno. Finally, we gratefully thank the anonymous participants to the questionnaire and all other contributions from any person or organization which may be lacking in this list.

Conflicts of Interest: The authors declare no conflict of interest. The funders had no role in the design of the study; in the collection, analyses, or interpretation of data; in the writing of the manuscript, or in the decision to publish the results.

\section{Appendix A}


Table A1. Attributes and values of cultural and natural heritage in Rufoli, Salerno. Source: elaboration of the authors.

Values (According to the Complex Social Value Theory, Fusco Giratd 1987)
furnaces are still in twe, the

Ancient furnaces made of bricks, with small openings to circulate air during the cooking process. 2 of them are still in use by the company "Fornaci De tiles

Tangible cultural heritage

Martino". Other furnaces

are owned by private subjects, but abandoned.
Social-Cultural value: the furnaces are a unique testimony of the past ways to produce clay tiles (cotto) the local community recognize the furnaces and tradition of cotto making for local identity.
Environmental value: the furnaces represent a "circular" production model based on natural resources of recovery of pieces of tiles allows to avoid wastes and products. on site; a traditional process reuse materials for new
Economic value: two clay tiles is a high-level

Intrinsic Value: the furnaces are a unique testimony of the permanence over design product of artisas quality, each tile is different from the other; this make the production demanded for high-quality architectural design; educational and tourism activities (visits, workshops) are active but could be strengthened; a potential fo strengthened; a potential for
recovery of other furnaces can be exploited. centuries of the clay tiles
(cotto) making tradition; a circular model of production, based on local resources and no waste, is manifested in the furnaces site; the "spirit" of cotto making to provide materials
for houses and buildings is still present in the site, still present in the site,
today represented by the entrepreneurial activities inspired by past values and oriented to the future.
Two of them have been recovered by the company "Fornaci De Martino" and are in use. Other furnaces are in a state of abandonment and degrade.
The only family today still

able to cook clay tiles in ancient furnaces is linked to the company of "Fornaci De Martino", owners of the two still working furnaces. This tradition has been

transferred from father to son orally; the moment of cooking lasts two days,

Tradition of clay tiles (cotto) following procedures of fire making following procedures of fire
making, windows closing making, windows closing and opening during the
diverse hours and according to winds and weather; the role of women was to support men in this effort being present during the days of cooking and providing them energy through food and wine. Sometimes external people are invited to attend. to attend.
Environmental value: the

Social-Cultural value: the tradition is a unique expression of cultural expression of cultural
diversity and history, still conserved after centuries but at high risk of disappearing after the present generation of cotto makers. grounded in a sustainable production model in synergy with the local environment; wind, sun, soil, water are the elements of this tradition, which reports to the prese close to the present the Nature coming from the past traditions.
Economic value: the intangible heritage has a high potential for sustainable economic value creation; the presence of this tradition can potentially greatly enhance the
attractiveness of the peripheral eastern area of Salerno.
Intrinsic Value: the tradition of cotto making is deeply embedded in the "spirit of the place", where the clay as primary material was present since ever; men worked in synergy with natural elements (wind, sun, water, soil ... ),

re-generating the atmosphere of the site over time.
The tradition is still alive, however it remains at high risk of disappearing after the present generation of cotto makers. 
Table A1. Cont.

\begin{tabular}{|c|c|c|c|c|c|c|}
\hline & $\begin{array}{c}\text { Attributes/ } \\
\text { Characteristics }\end{array}$ & \multicolumn{4}{|c|}{ Values (According to the Complex Social Value Theory, Fusco Girard 1987) } & State of Conservation \\
\hline $\begin{array}{l}\text { Clay hills caving sites } \\
\text { Natural heritage }\end{array}$ & $\begin{array}{l}\text { The hills nearby the } \\
\text { furnaces site is full of clay, } \\
\text { that was used since ever for } \\
\text { the production of tiles } \\
(\text { cotto). }\end{array}$ & $\begin{array}{l}\text { Social-Cultural value: } \\
\text { Cultural and social values } \\
\text { are linked to the awareness } \\
\text { of the importance of this } \\
\text { natural site for human } \\
\text { activities. }\end{array}$ & $\begin{array}{l}\text { Environmental Value: It has } \\
\text { a clear environmental value } \\
\text { linked to the ecosystem } \\
\text { services it provides, } \\
\text { particularly raw materials. }\end{array}$ & $\begin{array}{l}\text { Economic value: The } \\
\text { economic value is linked to } \\
\text { raw materials extraction, } \\
\text { and potentially to health } \\
\text { recreation services } \\
\text { associated to the presence of } \\
\text { a natural site. The site } \\
\text { represents the natural } \\
\text { environment that allowed } \\
\text { the production of cotto in } \\
\text { the area. }\end{array}$ & $\begin{array}{l}\text { Intrinsic Value: the tradition } \\
\text { of cotto have determined a } \\
\text { synergistic relationship } \\
\text { between man and natural } \\
\text { environment which, in the } \\
\text { time, was shaping by the } \\
\text { extractive activities related } \\
\text { to the presence of clay, } \\
\text { assuming a specific spatial } \\
\text { identity. }\end{array}$ & $\begin{array}{c}\text { The clay hill is conserved, } \\
\text { still in use as a source of } \\
\text { raw materials, according to } \\
\text { a sustainable production } \\
\text { model. }\end{array}$ \\
\hline $\begin{array}{l}\text { Archaeological remains } \\
\text { dating back to Roman time } \\
\text { Tangible cultural heritage }\end{array}$ & $\begin{array}{l}\text { Archaeological remains } \\
\text { dating back at least to } \\
\text { Roman time are present in } \\
\text { the whole eastern } \\
\text { peripheral area of Salerno. }\end{array}$ & $\begin{array}{l}\text { Social-Cultural value: The } \\
\text { archaeological remains are a } \\
\text { unique testimony of past } \\
\text { civilizations in the area, } \\
\text { with high cultural value. }\end{array}$ & $\begin{array}{l}\text { Environmental Value: is } \\
\text { potentially linked to the } \\
\text { green areas integrated with } \\
\text { archaeological remains. }\end{array}$ & $\begin{array}{l}\text { Economic value: this value } \\
\text { is linked to potential } \\
\text { attractiveness of the area for } \\
\text { visitors and residents. }\end{array}$ & $\begin{array}{l}\text { Intrinsic Value: The } \\
\text { uniqueness of the remains } \\
\text { could reinforce the "sense of } \\
\text { place" and identity of } \\
\text { citizens, if well valorised. }\end{array}$ & $\begin{array}{l}\text { Less-known, scarcely } \\
\text { valorized, partially still to } \\
\text { be discovered } \\
\text { archaeological sites. Local } \\
\text { associations take care of } \\
\text { them, however the } \\
\text { uniqueness of the remains } \\
\text { could represent an element } \\
\text { of attractiveness for the city. }\end{array}$ \\
\hline $\begin{array}{c}\text { Natural heritage } \\
\text { Tangible cultural heritage } \\
\text { (religious heritage present } \\
\text { in the site) } \\
\text { Intangible cultural heritage } \\
\text { (religious celebrations, place } \\
\text { linked to Salerno ancient } \\
\text { Medical School). }\end{array}$ & $\begin{array}{l}\text { The Mount is known for } \\
\text { being the highest mount in } \\
\text { the port city of Salerno ( } 953 \\
\mathrm{~m} \text { ). On the top of the } \\
\text { mountain there is a } \\
\text { religious site with a Church } \\
\text { dedicated to the holy Mary, } \\
\text { still active, in which a } \\
\text { traditional celebration is } \\
\text { organized every year. }\end{array}$ & $\begin{array}{l}\text { Social-Cultural value: The } \\
\text { Mount is a natural site in } \\
\text { which religious heritage is } \\
\text { present, holding cultural, } \\
\text { social and environmental } \\
\text { value. Local traditions } \\
\text { linked to the site include the } \\
\text { celebrations for the holy } \\
\text { Mary in the place of the } \\
\text { Church. }\end{array}$ & $\begin{array}{l}\text { Environmental Value: it is } \\
\text { believed that the Mount } \\
\text { was the place for collecting } \\
\text { medical herbs at the time of } \\
\text { the Salerno ancient Medical } \\
\text { School, dating back to the } \\
\text { Middle Age. }\end{array}$ & $\begin{array}{l}\text { Economic value: this value } \\
\text { can be potentially linked to } \\
\text { recreation activities. }\end{array}$ & $\begin{array}{l}\text { Intrinsic Value: the Mount } \\
\text { expresses the two most } \\
\text { important aspects of local } \\
\text { cultural identity. Indeed, on } \\
\text { one hand it has value as } \\
\text { memory of local spirituality } \\
\text { linked to the cult of holy } \\
\text { Mary, while on the other } \\
\text { hand it is linked with the } \\
\text { image of Salerno as the city } \\
\text { of health and wellbeing, } \\
\text { due to the presence of } \\
\text { Salerno Medical School } \\
\text { which still today represents } \\
\text { an element to be valorized } \\
\text { for a strong local brand } \\
\text { identity. }\end{array}$ & $\begin{array}{l}\text { The Mount was scarcely } \\
\text { maintained, however in the } \\
\text { last few years the } \\
\text { Municipality of Salerno } \\
\text { started recovery works to } \\
\text { make accessible the hiking } \\
\text { paths using public funding. } \\
\text { The local community } \\
\text { committed to opening up } \\
\text { connection paths with the } \\
\text { eastern neighbourhoods of } \\
\text { the city. The Church is not } \\
\text { very well conserved but } \\
\text { used. }\end{array}$ \\
\hline
\end{tabular}


Table A1. Cont.

Attributes/

\section{Characteristics}

Attributes/
Characteristics

Autochthonous grape "Sanginella"

Natural heritage

(as local typical agronomic

variety)
Intangible cultural heritage
The grape variety of "Sanginella" is an ancient variety, autochthonous of used in the past to make wine. the Salerno area, which of

State of Conservation s one of the few European

Social-Cultural value: the citizens of Salerno identified "Sanginellas votive food "Sanginilla as votive food dedicated to the patron, St Matthew, since its ripening period fell in the month dedicated to him. Furthermore, it was recognized as medical resource already used at the time of the Salerno Medical School to obtain medicines and remedies. available today. Until the first half of the 20th century it was the only table grape in Salerno. Its cultivation was positively conditioned by the climate and the favourable exposure to the sun of the Salerno area and, in turn, in turn, has conditioned the morphological structure of the land, transforming it into the characteristic terraced landscapes still visible today. Today this variety is not cultivated, out aves still
Economic value: there is ssociations to recover the variety enhancing its cultural, environmental and economic value.
Intrinsic Value: the

"Sanginella" has an identity value for the people of

Salerno as it is linked to the two most important aspects of local cultural identity: on the one hand the spiritual aspect linked to the cult of the patron, on the other hand the aspect linked to element represented by Salerno Medical School. Furthermore, the specific interaction between man and nature to cultivate this product has influenced the spatial transformation of landscape, characterizing it in the time. the strong brand identity
The variety is still conserved and available, but at high risk of avoid the loss of this peculiar natural and cultural heritage. disappearing. Recovery actions would be needed to 


\section{References}

1. Council of Europe. Framework Convention on the Value of Cultural Heritage for Society. Faro, Portugal, 2005. Available online: https://www.coe.int/en/web/culture-and-heritage/faro-convention (accessed on 22 April 2021).

2. Council of Europe. Heritage and Beyond; Council of Europe Publishing: Strasbourg, France, 2009; Volume 477, ISBN 9789287166357.

3. Zagato, L. The Notion of "Heritage Community" in the Council of Europe's Faro Convention. Its Impact on the European Legal Framework. In Between Imagined Communities of Practic; Göttingen University Pres: Göttingen, Germany, 2015; pp. 141-168. [CrossRef]

4. Feliciati, P. La valorizzazione dell'eredità culturale in Italia: Atti del convegno. IL Cap. Cult. Stud. Value Cult. Herit. 2016, 5, 25.03.2017.

5. European Commission. Towards an Integrated Approach to Cultural Heritage for Europe; European Commission: Brussels, Belgium, 2014. Available online: https:/ / eur-lex.europa.eu/legal-content/EN/TXT/PDF/?uri=CELEX:52014DC0477\&from=en (accessed on 13 December 2020).

6. European Commission. Getting Cultural Heritage to Work for Europe Report of the Horizon 2020 Expert Group on Cultural Heritage; European Commission: Brussels, Belgium, 2015.

7. UNESCO. Culture Urban. Future: Global Report on Culture for Sustainable Urban. Development; UNESCO: Paris, France, 2016.

8. United Nations. Habitat III Issue Papers 4-Urban. Culture and Heritage; United Nations: New York, NY, USA, 2015.

9. European Parliament TEXTS ADOPTED P8_TA-PROV(2017)0140 European Year of Cultural Heritage ***I 2017. Available online: https:/ / www.europarl.europa.eu/doceo/document/TA-8-2017-0140_EN.pdf (accessed on 17 September 2020).

10. Throsby, D. Cultural Capital. J. Cult. Econ. 1999, 23, 3-12. Available online: https:/ EconPapers.repec.org/RePEc:kap:jculte:v:23:y: 1999:i:1:p:3-12 (accessed on 3 November 2020). [CrossRef]

11. Throsby, D. Economics and Culture; Cambridge University Press: Cambridge, UK, 2001.

12. Ost, C. A Guide for Heritage Economics in Historic Cities—Values, Indicators, Maps, and Policies; ICHEC Brussels School of Management: Brussels, Belgium, 2009.

13. Ost, C. Mapping Heritage Economics for Spatial Analysis in Historic City Cores. In The Economics of Uniqueness. Investing in Historic City Cores and Cultural Heritage Assets for Sustainable Development; Licciardi, G., Amirtahmasebi, R., Eds.; The World Bank: Washington, DC, USA, 2012; pp. 245-283.

14. ICOMOS. Guidance on Heritage Impact Assessments for Cultural World Heritage Properties; ICOMOS: Paris, France, 2011.

15. UNESCO. Recommendation on the Historic Urban Landscape, Including a Glossary of Definitions. Available online: https: //whc.unesco.org/uploads/activities/documents/activity-638-98.pdf (accessed on 17 September 2020).

16. United Nations. New Urban Agenda. United Nations Conference on Housing and Sustainable Urban Development (Habitat III). 2017. Available online: https:/ / uploads.habitat3.org/hb3/NUA-English-With-Index-1.pdf (accessed on 15 November 2020).

17. Pinton, S.; Zagato, L. Cultural Heritage Scenarios 2015-2017; Edizioni Ca' Foscari: Venezia, Italy, 2017 ; ISBN 9788869691799. Available online: https:/ / edizionicafoscari.unive.it/media/pdf/books/978-88-6969-225-3/978-88-6969-225-3_MQpSP8B.pdf (accessed on 10 March 2021).

18. EUTROPIAN. Funding the Cooperative City; Patti, D., Polyák, L., Eds.; Cooperative City Books: Vienna, Italy, 2017; ISBN 978-3-9504409-0-4.

19. Garzillo, C.; Balenciaga, I.; Izulain, A.; Rangil-Escribano, T.; Wildman, A. Circular Governance Models for Adaptive Reuse of Cultural Heritage, Horizon 2020 CLIC Deliverable D3.4. 2019. Available online: https:/ /www.clicproject.eu/files/D3-4.pdf (accessed on 17 December 2020).

20. Bosone, M.; Micheletti, S.; Gravagnuolo, A.; Garzillo, C.; Wildman, A. Towards a circular governance for the adaptive reuse of cultural heritage. Bdc. Boll. Cent. Calza Bini 2019, 19, 279-305. [CrossRef]

21. Cerquetti, M.; Nanni, C.; Vitale, C. Managing the landscape as a common good? Evidence from the case of "Mutonia" (Italy). Land Use Policy 2019, 87, 104022. [CrossRef]

22. Ostrom, E. Governing the Commons; Cambridge University Press: Cambridge, UK, 1990.

23. Hess, C. Mapping the New Commons. SSRN Electron. J. 2008. Available online: https://surface.syr.edu/cgi/viewcontent.cgi? article $=1023 \&$ context $=$ sul (accessed on 15 December 2020). [CrossRef]

24. European Commission Study of Heritage Houses for Europe. Available online: https://op.europa.eu/it/publication-detail/-/ publication/bc6dd18f-ddba-11e9-9c4e-01aa75ed71a1/language-fr (accessed on 26 January 2021).

25. Cerreta, M.; La Rocca, L.; Elefante, A. San Sebastiano del Monte dei Morti Living Lab (SSMOLL): Un processo di riuso adattivo community-driven. In Proceedings of the LVII Incontro di Studi Ce.S.E.T. Sviluppo Sostenibile, Economia e Città Circolare: Processi e metodi di valutazione, Naples, Italy, 12-13 December 2019.

26. Garzillo, C. Artistic and Curatorial Power in Cities' Historic Spaces. Eur. J. Creat. Pract. Cities Landsc. 2020, 3, 139-148. [CrossRef]

27. Fusco Girard, L.; Gravagnuolo, A. Circular economy and cultural heritage/landscape regeneration. Circular business, financing and governance models for a competitive Europe. Bdc. Boll. Cent. Calza Bini 2017, 1, 35-52.

28. Fusco Girard, L. Implementing the circular economy: The role of cultural heritage as the entry point. Which evaluation approaches? Bdc. Boll. Cent. Calza Bini 2019, 19, 245-277. [CrossRef] 
29. Johnson, S.; Perry, W. The Synonymous, Etymological, and Pronouncing English Dictionary: In Which the Words Are Deduced from Their Originals, Their Part of Speech Distinguished, Their Pronunciation Pointed Out, and Their Synongma Collected; John Walker: London, UK, 1805.

30. Hardin, G. The Tragedy of the Commons. Science 1968, 162, 1243-1248. [CrossRef]

31. Ostrom, E.; Gardner, R.; Walker, J. Rules, Games, and Common-Pool Resources; Michigan Publishing: Ann Arbor, MI, USA, 1994.

32. Santagata, W.; Bertacchini, E.; Bravo, G.; Marrelli, M. Cultural Commons and Cultural Communities. In Proceedings of the 13th Biennial Conference of the International Association for the Study of the Commons, Hyderabad, India, 10-14 January 2011; pp. 10-14. Available online: https://dlc.dlib.indiana.edu/dlc/bitstream/handle/10535/7359/297.pdf? sequence=1 (accessed on 13 October 2020).

33. Ostrom, E. Design Principles and Threats to Sustainable Organizations That Manage Commons. Workshop Working Paper W99-6. 1999. Available online: http:/ / dlc.dlib.indiana.edu/dlc/bitstream/handle/10535/5465/Design\%20Principles\%20and\% 20Threats $\% 20$ to $\% 20$ Sustainable $\% 20$ Organizations $\% 20$ That $\% 20$ Manage $\% 20$ Commons.pdf? sequence=1\&isAllowed=y (accessed on 13 October 2020).

34. Richerson, P.J.; Boyd, R. Not by Genes Alone: How Culture Transformed Human Evolution. Biol. Philos. 2008, 23, 293-299. [CrossRef]

35. Senato della Repubblica Italiana Disegno di Legge Delega al Governo per la Modifica del Codice Civile in Materia di beni Pubblici. 2010. Available online: https:/ / www.senato.it/service/PDF/PDFServer/DF/217244.pdf (accessed on 17 September 2020).

36. Sacconi, L.; Ottone, S. Beni Comuni e Cooperazione; Il Mulino: Bologna, Italy, 2015; ISBN 978-8815253767.

37. United Nations. The Universal Declaration of Human Rights. 1948, pp. 1-8. Available online: https://www.ohchr.org/EN/ UDHR/Documents/UDHR_Translations/eng.pdf (accessed on 14 October 2020).

38. Carmosino, C. Il Valore del Patrimonio Culturale fra Italia e Europa. La Convenzione Quadro del Consiglio d'Europa sul Valore del Patrimonio Culturale per la società. Aedon 2013, 1. Available online: http:/ /www.aedon.mulino.it/archivio/2013/1 / carmosino.htm (accessed on 13 December 2020).

39. Fusco Girard, L. Risorse Architettoniche e Culturali: Valutazioni e Strategie di Conservazione; Franco Angeli: Milano, Italy, 1987.

40. Bonesio, L. Paesaggio, Identità e Comunità Tra Locale e Globale; Mimesis Edizioni: Milano, Italy, 2017; ISBN 978-88-5754-512-7.

41. Schofield, J. Heritage expertise and the everyday: Citizens and authority in the twenty-first century. In Who Needs Experts? Counter-Mapping Cultural Heritage; Schofield, J., Ed.; Ashgate Publishing: Farnham, UK, 2014; pp. 1-11. ISBN 9781472401786.

42. ICOMOS. Delhi Declaration on Heritage and Democracy. 2017. Available online: https://www.icomos.org/images/ DOCUMENTS/Charters/GA2017_Delhi-Declaration_20180117_EN.pdf (accessed on 17 October 2020).

43. Poulios, I. Discussing strategy in heritage conservation: Living heritage approach as an example of strategic innovation. J. Cult. Herit. Manag. Sustain. Dev. 2014, 4, 16-34. [CrossRef]

44. Fairclough, G.; Dragićević-Šešić, M.; Rogač-Mijatović, L.; Auclair, E.; Soini, K. The Faro Convention, a New Paradigm for Socially-and Culturally-Sustainable Heritage Action? Culture 2014, 8, 10-20.

45. Turner, R.K.; Paavola, J.; Cooper, P.; Farber, S.; Jessamy, V.; Georgiou, S. Valuing nature: Lessons learned and future research directions. Ecol. Econ. 2003, 46, 493-510. [CrossRef]

46. ICOMOS. Habitat III Preparatory Process: Urban Dialogue Reports-“Social Cohesion and Equity” 2015. Available online: https:/ / habitat3.org/the-new-urban-agenda/preparatory-process/urban-dialogue-reports/urban-dialogues-draft-zerosummaries/ (accessed on 19 December 2020).

47. Fusco Girard, L.; Nocca, F.; Gravagnuolo, A. Matera: City of nature, city of culture, city of regeneration. Towards a landscapebased and culture-based urban circular economy. Aestimum 2019, 74, 5-42. [CrossRef]

48. Adelman, C. Kurt Lewin and the Origins of Action Research. Educ. Action Res. 1993, 1. [CrossRef]

49. Masters, J. The history of action research. In Action Research Electronic Reader; Hughes, I., Ed.; The University of Sydney: Camperdown, Australia, 1995. Available online: http:/ / www.fionawangstudio.com/ddcontent/Web/action_research/readings/ Masters_1995_history\%20of\%20action\%20research.pdf (accessed on 19 March 2021).

50. Mills, C.W. The Sociological Imagination. Miss. Val. Hist. Rev. 1959, 46, 355-356. [CrossRef]

51. Olejniczak, K.; Borkowska-Waszak, S.; Domaradzka-Widła, A.; Park, Y. Policy labs: The next frontier of policy design and evaluation? Policy Politics 2020, 48, 89-110. [CrossRef]

52. Olejniczak, K.; Borkowska-Waszak, S.; Domaradzka-Widla, A.; Park, Y. The Craft of Policy Labs: An Overview of Methods Applied for Development and Testing of Policy Solutions. In the Rise of Policy Labs. In Proceedings of the Third International Conference on Public Policy (ICPP3), Singapore, 28-30 June 2017.

53. Avallone, G. Introduzione alla Tesi di Laurea Magistrale In Architettura, Università di Napoli Federico II. Dipartimento di Architettura. 2017.

54. Fornaci de Martino. Available online: www.fornacedemartino.it. (accessed on 19 October 2020).

55. Fondo Ambiente Italiano. Available online: www.fondoambiente.it. (accessed on 13 September 2020).

56. Rubino, G. Le Fabbriche del Sud: Architettura e Archeologia del Lavoro; Giannini: Naples, Italy, 2011.

57. Cuomo di Caprio, N. Ceramica in Archeologia, 2. Antiche Tecniche di Lavorazione e Moderni Metodi di Indagine; L'Erma di Bretschneider: Rome, Italy, 2007.

58. Persico, P. Identità e Sviluppo; Pietro La Veglia editore: Salerno, Italy, 1997.

59. Ler, S. Le Fornaci di Rufoli. la Via Dell'acqua, la Via del Fuoco; La Veglia editore: Salerno, Italy, 1984. 
60. Cuomo, C. L'Impastacrita. Camporiv. Trimest. Cult. Del Mezzog. 1981, 7, 41-43.

61. Sinno, A. Commercio e Industrie Nel Salernitano Dal XIII Ai Primordi del XIX Secolo; Camera di Commercio Industria e Agricoltura di Salerno: Salerno, Italy, 1954.

62. Panebianco, V. La Colonia Romana di Salernum: Introduzione Allo Studio di Salerno Romana; Linotypografia Spadafora: Salerno, Italy, 1997.

63. UNESCO. The Hul Guidebook. Managing Heritage in Dynamic and Constantly Changing Urban Environments. A Practical Guide to Unesco's Recommendation on the Historic Urban Landscape; World Heritage Institute of Training and Research for the Asia and the Pacific Region (WHITRAP): Shanghai, China; Ballarat, Australia, 2016.

64. Smith, L.W. Stakeholder analysis: A pivotal practice of successful projects. In Proceedings of the Project Management Institute Annual Seminars \& Symposium, Houston, TX, USA, 7 September 2000; Project Management Institute: Newtown Square, PA, USA, 2000.

65. Project Management Institute. A Guide to the Project Management Body of Knowledge: PMBOK Guide, 5th ed.; Project Management Institute: Newtown Square, PA, USA, 1996; ISBN 9781628251845.

66. Cerreta, M.; Malangone, V. Valutazioni multi-metodologiche per il Paesaggio Storico Urbano: La Valle dei Mulini di Amalfi. Bdc. Boll. Cent. Calza Bini 2014, 14, 39-60. [CrossRef]

67. Reed, M.S.; Graves, A.; Dandy, N.; Posthumus, H.; Hubacek, K.; Morris, J.; Prell, C.; Quinn, C.H.; Stringer, L.C. Who's in and why? A typology of stakeholder analysis methods for natural resource management. J. Environ. Manag. 2009, 90, 1933-1949. [CrossRef] [PubMed]

68. Dryzek, J.S.; Berejikian, J. Reconstructive Democratic Theory. Am. Polit. Sci. Rev. 1993, 87, 48-60. [CrossRef]

69. Pronti, A.; Nobile, G.; Pagliarino, E. La Stakeholder Analysis per la gestione dei beni comuni e delle risorse naturali: Metodologie e letteratura. Quad. IRCrES-CNR 2018, 4, 3-28. [CrossRef]

70. Fusco Girard, L.; Nijkamp, P. Le Valutazioni per lo Sviluppo Sostenibile della Città e del Territorio; Franco Angeli: Milano, Italy, 1997; ISBN 978-88-464-0182-3.

71. Fusco Girard, L.; Vecco, M. Genius Loci: The evaluation of places between instrumental and intrinsic values. Bdc. Boll. Cent. Calza Bini 2019, 19, 473-495. [CrossRef]

72. Fusco Girard, L.; Vecco, M. The "Intrinsic Value" of Cultural Heritage as Driver for Circular Human-Centered Adaptive Reuse. Sustainability 2021, 13, 3231. [CrossRef]

73. Fusco Girard, L. The circular economy in transforming a died heritage site into a living ecosystem, to be managed as a complex adaptive organism. Aestimum 2021, 77, 145-180. [CrossRef]

74. De la Torre, M. Values and Heritage Conservation. Herit. Soc. 2013, 60, 155-166. [CrossRef]

75. Costanza, R.; D’Arge, R.; de Groot, R.; Farber, S.; Grasso, M.; Hannon, B.; Limburg, K.; Naeem, S.; O’Neill, R.V.; Paruelo, J.; et al. The value of the world's ecosystem services and natural capital. Nature 1997, 387, 253-260. [CrossRef]

76. Pearce, D.; Atkinson, G.; Mourato, S. Total Economic Value. In Cost-Benefit Analysis and the Environment: Recent Developments; Organ. Econ. Co-Op. Dev: Paris, France, 2006; ISBN 9789264010055.

77. Turner, K. The Place of Economic Values in Environmental Valuation. In Valuing Environmental Preferences: Theory and Practice of the Contingent Valuation Method in the US, EU, and Developing Countries; Bateman, I.J., Willis, K.G., Eds.; Oxford University Press: Oxford, UK, 2001; pp. 17-41. ISBN 9780199248919.

78. Pearce, D.W.; Turner, R.K. Economics of Natural Resources and the Environment; JHU press: London, UK, 1989 ; ISBN 0745002250.

79. Council of Europe Faro Convention Network (FCN). Available online: https:/ /www.coe.int/en/web/culture-and-heritage/farocommunity\#portlet_56_INSTANCE_5mj12VH0zeQr (accessed on 13 September 2020).

80. Brown, J.; Isaacs, D. The World Café: Shaping our Future Through Conversations that Matter; Berrett-Koehler Publishers: San Francisco, CA, USA, 2005.

81. Pintossi, N.; Ikiz Kaya, D.; Pereira Roders, A. Adaptive Reuse of Cultural Heritage in Amsterdam: Identifying Challenges and Solutions through the Historic Urban Landscape Approach. In LDE Heritage Conference on Heritage and the Sustainable Development Goals: Proceedings; Pottgiesser, U., Fatoric, S., Hein, C., de Maaker, E., Pereira Roders, A., Eds.; TU Delft Open: Delft, The Netherlands, 2021; pp. 304-314.

82. Pintossi, N.; Ikiz Kaya, D.; Pereira Roders, A. Assessing Cultural Heritage Adaptive Reuse Practices: Multi-Scale Challenges and Solutions in Rijeka. Sustainability 2021, 13, 3603. [CrossRef]

83. Ost, C.; Saleh, R. Horizon 2020 CLIC Deliverable D3.3 Maps of Landscape Perceptions. 2019. Available online: https://www. clicproject.eu/files/D3-3.pdf (accessed on 25 November 2020).

84. Weick, K.E. Sensemaking in Organizations, 1st ed.; SAGE Publications: Thousand Oaks, CA, USA, 1995; ISBN 978-0803971776.

85. Cerreta, M.; Giovene di Girasole, E. Towards Heritage Community Assessment: Indicators Proposal for the Self-Evaluation in Faro Convention Network Process. Sustainability 2020, 12, 9862. [CrossRef] 